
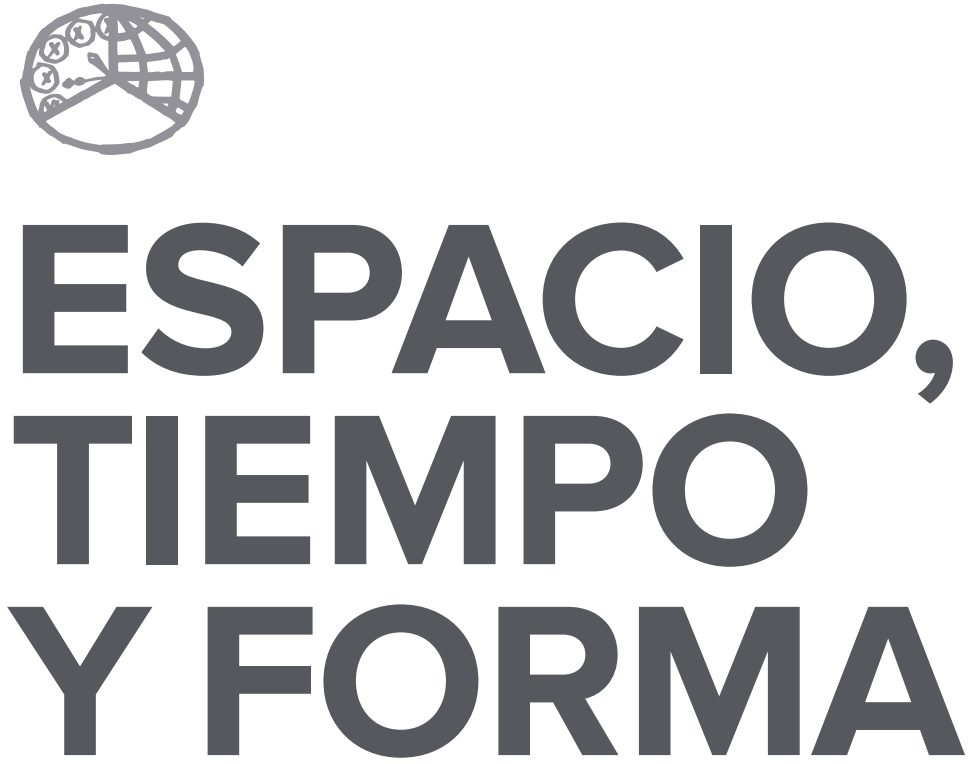

AÑO 2018

ISSN 0214-9745

E-ISSN 2340-1362

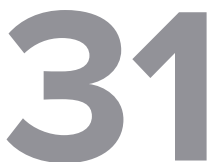

SERIE III HISTORIA MEDIEVAL

REVISTA DE LA FACULTAD DE GEOGRAFÍA E HISTORIA 



\section{ARTÍCULOS · ARTICLES}





\title{
LA ÉTICA ARISTOTÉLICA EN CASTILLA: LAS BIBLIOTECAS UNIVERSITARIAS MEDIEVALES Y PRERRENACENTISTAS
}

\section{THE ARISTOTELIAN ETHICS IN CASTILE: THE MEDIEVAL AND PRE-RENAISSANCE UNIVERSITY LIBRARIES}

\author{
María Díez Yáñez
}

Recepción: 2017/12/31 - Comunicación de observaciones de evaluadores: 2018/02/5 .

Aceptación: 2018/03/27

DOI: http://dx.doi.org/10.5944/etfiii.31.2018.20767

\section{Resumen ${ }^{2}$}

Todavía en demasiadas ocasiones se ha dejado de lado el panorama hispánico en el contexto europeo. Por eso presento aquí un estudio de los ejemplares aristotélicos conservados en las bibliotecas catedralicias y universitarias del reino de Castilla. La revisión de los inventarios y catálogos de manuscritos e incunables proporciona un análisis cuantitativo y cualitativo del fondo aristotélico. El objetivo es proporcionar un corpus de los antecedentes necesarios para una mejor comprensión y estudio de la recepción de la moral aristotélica en la Castilla tardomedieval y renacentista.

La cultura cortesana se sirve de la moral de Aristóteles para construir y difundir un discurso a favor de la monarquía. Una de las vías de acceso más importantes al texto aristotélico es la universitaria. A partir de ahí, resultarán especialmente interesantes las adaptaciones y transmisiones de la Ética en los contextos aristocráticos. La transmisión del texto de la Ética aristotélica en Castilla responde a factores europeos y a características propias del contexto hispánico. De esta manera, se podrán perfilar las peculiaridades del aristotelismo en la península ibérica, a la vez que completar el recorrido del aristotelismo en Europa.

1. École Normale Supérieure de Lyon (Francia). C.e.: maria.diez-yanez@ens-lyon.fr

2. Este trabajo ha sido realizado al amparo de las investigaciones realizadas en el Proyecto de investigación 2016-2018, Miembro del Proyecto de Investigación Bibliografía Española de Textos Antiguos (Beta) II, referencia FFI201563625-C2-1-P. 2013-2015, Miembro del Proyecto de Investigación Bibliografía Española de Textos Antiguos (Beta), con referencia $\mathrm{FFI}_{2012-35522 .}$ 


\title{
Palabras clave
}

Aristotelismo; Universidad; Castilla; moral; Edad Media; Renacimiento.

\begin{abstract}
All too often, the Hispanic case in history has been neglected in European-wide studies. For this reason, we will study the works of Aristotle held in cathedral and university libraries in the kingdom of Castile. A quantitative and qualitative analysis of the manuscripts and incunabula of Aristotelian writings by way of the inventories of Castilian universities will be undertaken in order to create a corpus of existing works and determine the reception of Aristotelian moral philosophy in late-medieval and Renaissance Castile.

Courtly culture adopted Aristotelian moral theory to construct and transmit a discourse in favour of monarchy. The university is one of the most important centres where one could get access to Aristotelian texts. From this basis, we will study the adaptation and transmission of Aristotle's Ethics in an aristocratic context. The transmission of the text of Aristotle's Ethics in Castile responds to European factors as well as to characteristics derived from the particular Hispanic context. This study enhances our understanding of the characteristics of Aristotelianism in the Iberian Peninsula, and allows us to complete the wider picture in Europe.
\end{abstract}

\section{Keywords}

Aristotelianism; University; Castile; Moral Philosophy; Middle Ages; Renaissance. 
PRESENTO a continuación un estudio de los inventarios de las bibliotecas catedralicias y universitarias castellanas. Selecciono la información que contribuye a perfilar la evolución de la recepción de la Ética aristotélica en este panorama. Me centro en el caso castellano, como una de las partes esenciales del conjunto del territorio hispánico en el desarrollo de la monarquía y del futuro estado moderno español. ${ }^{3}$

El análisis es de carácter cuantitativo y cualitativo. Así, a través de la muestra del número de ejemplares aristotélicos dentro del total recogido en los inventarios, se especifican aquellos que se refieren directa o indirectamente a la Ética aristotélica. Sin perder de vista la cautela debida en el tratamiento de los inventarios, este panorama funciona como antecedente del ambiente intelectual universitario que servirá de punto de partida, de puente o de referencia para las evoluciones, adaptaciones y recepciones del Aristotelismo en el terreno hispánico.

\section{ESCUELAS CATEDRALICIAS CASTELLANAS}

En la medida en que las escuelas catedralicias fueron el origen de la intelectualidad en Occidente, también en Castilla éstas ocuparon un lugar importante en la transmisión del corpus aristotélico. Fue en este tipo de studia donde se generaron las traducciones y versiones de la Ética aristotélica. A partir de ahí pueden entenderse muchas de las demás versiones y adaptaciones de esta filosofía moral en sus distintos ámbitos y en sus diferentes maneras.

\subsection{TOLEDO}

Toledo fue un centro de confluencia intelectual para Oriente y Occidente. ${ }^{4}$ Esta encrucijada de culturas se reflejó también en el intercambio de textos.

3. Por falta de espacio y tiempo me limito aquí al caso castellano, pero valgan como referente los siguientes estudios sobre el aristotelismo aragonés para completar el conjunto de la recepción de la Ética aristotélica: EsCOBAR CHICO, Ángel: «Aristoteles pictus: vicisitudes de la iconografía aristotélica en la España medieval y renacentista», Atalaya, 15 (2015), pp. 1-21, [fecha de consulta: 6 de noviembre 2017] URL: 〈https://atalaya.revues.org/1441>; «Hacia una caracterización de la transmisión aristotélica en la Cataluña medieval», Anuario de Estudios Medievales, 45: 1 (2015), pp. 299-330; «Presencia de Aristóteles en el Fondo Antiguo de las bibliotecas aragonesas. Apuntes para un repertorio sistémático», Alazet, 14 (2002), pp. 123-137; «Aristoteles Hispanus: Transmisión textual y pervivencia literaria de Aristóteles en España (hasta 1600)», en: Prato, G (ed.): I manoscritti greci tra riflessione e dibattito. Atti [...]. Florencia, Gonnelli, 2000, pp. 715-718. Y los de Cuenca i Almenar, Salvador: Compendio de la Ética Nicomaquea (siglo XV). Edición crítica y estudio. Zaragoza, Prensas Universitarias de Zaragoza, 2016; «El compendio de la Ética Nicomaquea (siglo XV): relaciones entre los manuscritos castellano-aragoneses y el testimonio catalán», Romance Philology, 70 (2016), pp. 283-294; «L’Ėtica nicomaquea d'Aristòtil en un compendi català del segle XV», Anuari de la Societat Catalana de Filosofia, XXIII, (2012), pp. 7-119; «Un exemple d'amplificació en els comentaris de L'Ėtica nicomaquea (1137a-b): el setge de València de 1364, els estrangers castellans i la virtut de l'equitat», en CASABAN MOYA. Enric (ed.): XIX Congrés Valencià de Filosofia. Valencia, Universidat de Valencia/Universitat Jaume I, 2012, pp. 75-82.

4. Es precisamente en el sentido de que Toledo fue lugar de reunión de un «conjunto de estudiosos, en unas 
Por otro lado, el clero era el propietario de la incipiente biblioteca aneja al Studium y la cabeza del cabildo era el arzobispo. La realidad de esta relación eclesiástica e intelectual queda constatada en la formación de su biblioteca, que incluye 66 volúmenes, según el inventario que se realizó siendo canónigo tesorero don Rodrigo Yuanes a mediados del siglo XIll..$^{5}$ Aunque los datos con los que contamos son incompletos, sí sabemos qué libros de la biblioteca pertenecían a Gonzalo Pétrez y cuáles fueron donados por el cardenal Zelada en el siglo XVII.

\subsubsection{Las escuelas alfonsíes: la presencia de la corte regia en la universidad y la donación del arzobispo Gonzalo García Gudiel (Gonzalo Pétrez) (ca. 1238-1299)}

Aunque no se puedan constatar con precisión las características de un sistema educativo determinado, Alfonso X el Sabio (I252-I284) consideraba que un Estudio General debía estar dotado de las cátedras de Gramática, Lógica, Retórica, Leyes y Decretos. ${ }^{6} \mathrm{La}$ actividad cultural promovida por el rey durante este período tuvo en cuenta la recepción de la Moral aristotélica (la figura y obra de Hermann el Alemán y Brunetto Latini son una muestra), así como el empleo de testimonios de obras pseudo-aristotélicas, que también transmitían, de forma más o menos directa y de manera ecléctica, máximas de corte aristotélico. ${ }^{7}$

Bajo la actividad episcopal de don Rodrigo Jiménez de Rada (I209-I247) se fundaron las escuelas regias. En ellas queda manifiesta una vez más la relación entre la institución eclesiástica y la corte regia, que contribuyen a la configuración de las coordenadas culturales y políticas del reino.

Como la biblioteca de la Escuela de Toledo debe parte de su formación a la labor de Gonzalo Pétrez, arzobispo en esa ciudad desde I280-I298, expongo a continuación la información que interesa sobre los libros que contenía. ${ }^{8}$

\footnotetext{
mismas bibliotecas, con unos mismos procedimientos de trabajo, trabajando en un mismo campo» lo que justifica que se pueda llamar a este centro intelectual «Escuela» (MENÉNDEz PIDAL, Ramón: España, eslabón entre la Cristiandady el Islam. Madrid, Espasa Calpe, 1956, p. 30).

5. Benito RUANo, Eloy: «Ámbito y ambiente de la «Escuela de Traductores de Toledo». Espacio, Tiempo y Forma, Serie 3. Historia Medieval, 13 (2000), pp. 13-28, disponible en <http://revistas.uned.es/index.php/ETFIII/issue/view/309> [acceso 17 noviembre 2017] y GonzÁLVez RuIz, Ramón: Hombres y libros de Toledo. Madrid, Fundación Ramón Areces, 1997, p. 34.

6. CACHO BLECUA, Juan Manuel y LACARRA, María Jesús: Historia de la literatura española. Volumen 1. entre la oralidad y la escritura: la Edad Media, dir. José Carlos-Mainer y cord. Gonzalo Pontón, Barcelona, Crítica, 2012, pp. 217 y 229.

7. Ferreiro Alemparte, Jaime: «Rececpción de las Éticas y de la Política de Aristóteles en las Siete Partidas del Rey Sabio», Glossae: Revista de Historia del Derecho Europeo, 1 (1988), pp. 97-33, disponible en <https://dialnet.unirioja.es/ servlet/revista?codigo=625> [acceso 20 noviembre 2017] y BOLTON HOLLOWAY, Julia: «Diplomacy and Literature: Alfonso el Sabio's Influence on Brunetto Latino, Maestro di Dante Alighieri», en La città e il libro. II manoscritto, la miniatura. Firenze e la Spagna. Florencia, Accademia delle Arti del Disegno, 2002, disponible en <http://www.florin.ms/bethza. html\#embassy> [acceso 20 noviembre 2017].

8. Hernández, Francisco J. y Linehan, P.: The Mozarabic Cardinal. The Life and Times of Gonzalo Pérez Gudiel. Florencia, Sismel-Edizioni del Galluzzo, 2004.
} 
A partir de los inventarios de I273 y I280 quedan constatados II8 ejemplares. 25 pertenecen a obras aristotélicas: 5 a la Ética, de las cuales dos se corresponden con la traducción de Hermann el Alemán a partir de la versión árabe [Inventario I273, 23 y 24] y los otros tres a la versión de Grosseteste [Inventario I280, 20, 59, 72]; entre estos últimos uno incluye también una versión de la Política [Inventario I280, 59]. ${ }^{9}$

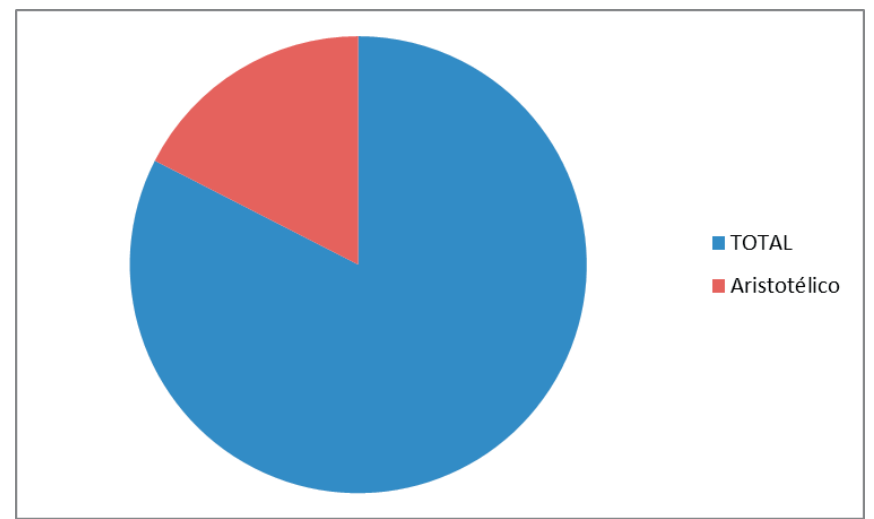

FIGURA 1. CORPUS ARISTOTÉLICO EN EL TOTAL DE MANUSCRITOS DE LA BIBLIOTECA EPISCOPAL DE GONZALO PÉTREZ. (Elaboración propia).

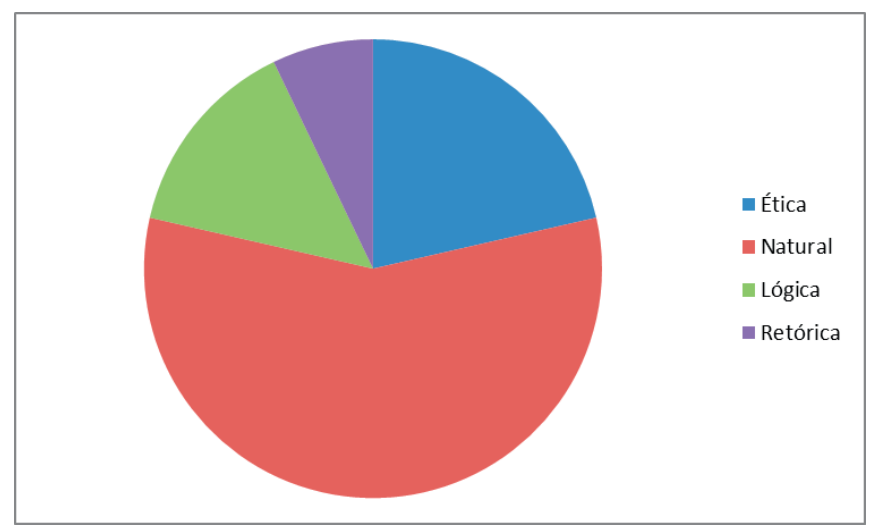

FIGURA 2. OBRAS ARISTOTÉLICAS EN EL TOTAL DE MANUSCRITOS DE LA BIBLIOTECA EPISCOPAL DE GONZALO PÉTREZ. (Elaboración propia).

La Biblioteca de Gonzalo Pétrez, por tanto, refleja una considerable recepción de la obra moral de Aristóteles en el siglo XIII. También cabe destacar la presencia de testimonios de la tradición oriental árabe, así como de la occidental latina: ambas corrientes resultan esenciales para comprender el proceso de la recepción

9. Gonzálvez Ruiz, Hombres y libros de Toledo..., pp. 426-444 y 467-512. 
aristotélica hispánica y para comprobar de qué manera el criterio academicista de las bibliotecas universitarias explica también el tipo de obras aristotélicas que conservaban, pues los intereses de los destinatarios condicionan el tipo de obras, género y fuentes de referencia.

\subsection{BURGOS Y SORIA (BURGO DE OSMA): CENTRO DE ESTUDIOS DE CARÁCTER CLERICAL}

El eje político-administrativo y burocrático tenía sus límites en Burgos y Toledo. Este enclave fue fundamental en el desarrollo de la política castellana y fue adquiriendo mayor importancia económica como centro del comercio urbano, cuestión que le interesaba controlar a la Corona. ${ }^{\text {Io }}$ También el cabildo de la ciudad se preocupaba de dar formación letrada a sus clérigos, para cuyo objetivo reunió a un cuerpo profesional y técnico apto para llevar a cabo las diversas actividades, no solo religiosas, sino también jurídicas y económicas, que exigían las determinadas circunstancias. ${ }^{\text {II }}$

\subsubsection{La catedral de Burgos}

En el conjunto de inventarios conservados en la diócesis de Burgos, el número de libros litúrgicos es el más reducido, frente a los títulos de Derecho canónico y civil, y la materia de Teología sigue siendo la predominante. Entre los libros de Artes Liberales se registran las gramáticas de Papias, Alexandro de Villadei y Guarino de Verona. En el ámbito de la moral, se encuentran obras de Cicerón y Séneca, así como el género de la literatura de vicios y virtudes representado en la obra de Guillermo Peraud. Asimismo, se localizan la Ética y la Retórica de Aristóteles y unos Comentarios a la Política de Leonardo Bruni. ${ }^{\mathrm{I2}}$ También se incluye un De regimine principum y De esentia nobilitatis de Montemagno, localizados en la biblioteca del obispo don Luis Osorio de Acuña (I456-I495). ${ }^{\text {I3 }}$ La materia de Retórica queda representada por los Ars dictaminis y Ars praedicandi y por Cicerón, Brunetto Latini, Aristóteles y Petrarca. Incluye una sección para obras históricas y, por último, las Artes que componen el Quadrivium quedan también

10. Paulas Cañas Gálvez, Francisco de: Burocracia y cancillería en la corte de Juan II de Castilla (1406-1454). Estudio institucional y prosopográfico. Salamanca, Ediciones Universidad de Salamanca, 2009.

11. Ramos Merino, Juan Luis: «La librería de la Catedral de Burgos en el siglo XV: una aproximación», Boletín de la Institución Fernán González, 1: 266 (2003), pp. 181-192.

12. Que pertenecieron al canónigo Sánchez de Arévalo (GuIJARro González, Susana: Maestros, escuelas y libros. El universo cultural de las catedrales en la Castilla medieval. Madrid, Dykinson, 2004, Anexo, ítems 1229-1231).

13. López Martínez, Nicolás: «La biblioteca de don Luis de Acuña en 1496», Hispania: Revista española de historia 78 (1960), pp. 81-110. 
representadas en una obra de Geometría y Aritmética y en los Libros naturales de Aristóteles (estos también procedentes de la biblioteca de don Luis de Acuña). ${ }^{\text {I4 }}$

\subsubsection{La biblioteca de don Luis Osorio de Acuña (1496)}

No encontramos ningún ejemplar de la obra aristotélica hasta que analizamos el inventario del obispo don Luis de Acuña de I496, en donde consta la presencia de 8 obras aristotélicas entre los 363 ejemplares. De la moral, dos son testimonios de la Ética aristotélica y un tercero de los Comentarios tomistas a la Ética. Además, se menciona un ejemplar del De regimine principum de Gil de Roma. ${ }^{15}$

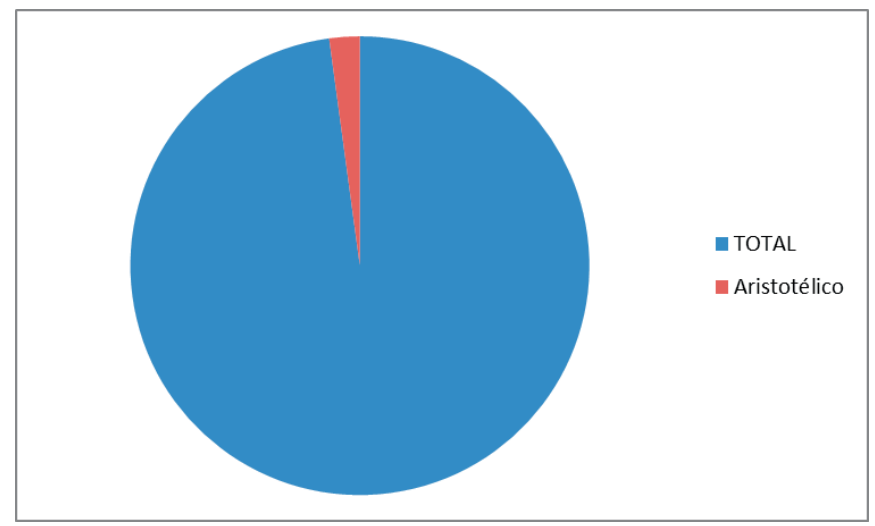

FIGURA 3. CORPUS ARISTOTÉLICO EN EL TOTAL DE MANUSCRITOS DE LA ÉTICA EN LA BIBLIOTECA DE DON LUIS DE ACUÑA. (Elaboración propia).

Es en esta catedral donde encontraremos más adelante una figura esencial para el aristotelismo hispánico: la del obispo Alonso de Cartagena (I386-I456), canónigo de Burgos desde I429 y obispo desde I435. Sin embargo, esta biblioteca no conserva ninguna de sus obras. ${ }^{16}$

14. GuijarRo GonzÁlez, Susana: «Las escuelas y la formación del clero de las catedrales en las diócesis castellanoleonesas (siglos XI al XV)», en de la IGLESIA DUARTE, José Ignacio (coord.). X Semana de Estudios Medievales: la enseñanza en la Edad Media. Logroño, Instituto de Estudios Riojanos, 2000, pp. 61-96. Se localiza en concreto un libro de la Física de Aristóteles en el inventario del cabildo (GuIJARRo GonzÁlez: Maestros, escuelas y libros...., Anexo, ítem 1028).

15. López Martínez, Nicolás: «La biblioteca de don Luis de Acuña en 1496»...El testamento del obispo también incluye tres testimonios de la Retórica aristotélica, lo que es un signo más de las renovadas tendencias intelectuales. (Guijarro González, Susana: Maestros, escuelas y libros..., Anexo, ítems 1456, 1469 y 1480).

16. A pesar del deseo de Cartagena de conservar copias de sus obras en un armario junto a su sepultura, en la capilla de la Visitación de la catedral de Burgos, éste fue desgraciadamente saqueado. 


\subsection{EL CABILDO DE BURGO DE OSMA}

La biblioteca del cabildo de Burgo de Osma era rica en ejemplares de temática religiosa y litúrgica. También conservaba ejemplares de algunos clásicos como la Retórica de Cicerón y una obra de Terencio. Se citan en el inventario dos obras de Boecio (gran comentador de Aristóteles) y un comentario a la Metafísica de Gil de Colonia. ${ }^{17}$

\subsection{SIGÜENZA (1339)}

En Sigüenza se erigió el primer colegio-universidad de los reinos hispanos: el Colegio de San Antonio de Portaceli (I477), gracias al trabajo del arcediano de Almazán y canónigo de Toledo, Juan López de Medina (†I488), quien logró del cardenal Mendoza la aprobación de su fundación, más tarde confirmada por el pontífice en $1489 .^{18}$

Aída Portilla González ha identificado los ejemplares recogidos en los distintos inventarios medievales que conservamos de la biblioteca de la catedral siguntina. ${ }^{19}$ Se localizan 30 I ejemplares, de los cuales, restando los I3 no identificados, I4 se corresponden con materias de las Artes Liberales; 3 con obras de autores clásicos (De coniuratione Catilinae de Salustio, Las Heroidas de Ovidio y las Sátiras de Juvenal); 26 con materia de Derecho canónico; 15 con Derecho civil; I con materia hagiográfica; 75 con litúrgica; 29 con Sagradas Escrituras; 39 correspondientes a sermones; 73 con obras de Teología; 2 obras de Medicina; y 2 de Filosofía. Entre estas últimas es donde se localiza la única obra aristotélica que contiene la biblioteca: la traducción de la Metaphysica de Aristóteles efectuada por Guillermo de Moerbeke (I215-I286) en Toledo. ${ }^{20}$

17. Rojo OrCajo, Timoteo: Catálogo descriptivo de los códices que se conservan en la santa Iglesia Catedral de Burgo de Osma. Madrid, Tipografía de Archivos, 1929. Y Guijarro González, Susana: GuijArRo González, Susana: Maestros, escuelas y libros..., p. 156. Actualmente, sin embargo, esta biblioteca conserva el original del Duodenarium de Alonso de Cartagena (Cód.42) y el Memoriale virtutum (junto con un texto de Leonardo Bruni contra hypocritas) (Cód. 117). Charles Lohr documenta en esta biblioteca un ejemplar de la Summa moralium de Aristóteles. (Códice num. 49) (LOHR, Charles: Commentateurs d'Aristote au moyen-âge latin. Bibliographie de la littérature secondaire récente. Friburg, Editions universitaires, 1967, p. 347).

18. Portilla GonzÁlez, Aída: «El saber medieval en Castilla (ss. XIII-XIV): la biblioteca de la catedral de Sigüenza», Medievalismo, 24 (2014), pp. 321-351, p. 325, disponible en <http://revistas.um.es/medievalismo/issue/view/13161> [acceso 15 noviembre 2017].

19. El inventario A (IA), correspondiente a los libros del obispo D. Rodrigo (1192-1221) de principios del siglo XIII; el inventario B (IB), fechado en 1242; el C (IC) que data de principios del siglo XIV; y el inventario D (ID) datado en 1339. (Idem, p. 324).

20. La otra es el De consolation philosophiae de Boecio. 


\subsection{BIBLIOTECAS CAPITULARES DE CÓRDOBA Y SEVILLA}

El Statuto fecho en favor de los estudiantes, del 23 de agosto de I466, refleja la importancia que daban a las materias de Gramática, Lógica y Filosofía, formación previa a la que los clérigos recibirían en las principales universidades del reino de Castilla: Salamanca y Valladolid, o en el Colegio de San Clemente de Bolonia, al que algunos también tuvieron acceso. ${ }^{2 \mathrm{I}}$

La formación de la biblioteca de Córdoba responde a las donaciones del obispo Fernando de Mena, en I274; del deán Pedro de Ayllón, en I302; del maestrescuela Fernando González de Deza, en I424; del obispo Martín Fernández de Angulo, en I5I6; y la de manuscritos griegos de Juan Ginés de Sepúlveda, en I564. ${ }^{22}$

Los ejemplares manuscritos que contiene la biblioteca incluyen la temática de las ciencias sagradas (hagiografía medieval, liturgia y patrística) (Catedral de Córdoba, Ms. I59), tratados sobre pastoral y algunos tratados de vicios y virtudes (un ejemplo es el manuscritoini) y obras de moral de tipo ascético. ${ }^{23}$ De materia aristotélica, se localizan cuatro obras: dos de la Filosofía natural (uno es el comentario de Gil de Roma Com.in octo Libros Physicorum Aristotelis (Catedral de Córdoba, Ms. 69, ss. XIII-XIV) y otro de Tomás de Aquino (Catedral de Córdoba, Ms. 63, s. XIII); un ejemplar del comentario a la Metafísica, hecho por Jacobo de Alejandría y otro de santo Tomás de Aquino (Catedral de Córdoba, Ms. I29, ss. XIII-XIV); por último, un comentario a la Política de Pedro de Osma (Catedral de Córdoba, Ms. 136).

En el caso de los incunables, la materia que abunda es la teológica. Pero se encuentran también nueve obras aristotélicas, de las cuales cinco se corresponden con contenidos de Moral: La Ethica ad Nicomachum, libri decem. Politicorum libri octo (Catedral de Córdoba, Inc. 520), un volumen que contiene la Epistola ad Alexandrum Magnum, la Ethica ad Nicomachum y ad Eudemum, la Politica y la Oeconomica y las Magna Moralia, junto con obras de Lógica y Física aristotélicas (Catedral de Córdoba, Inc. 439). Todos los ejemplares están impresos en Venecia excepto uno, que se imprimió en Valencia (Catedral de Córdoba, Inc.615, que contiene la versión de la Ética, Económica y Política de Leonardo Bruni). Los demás ejemplares son los Comentarios de Averroes a la Opera aristotélica (Catedral de Córdoba, Inc. 5I7), los Comentarios de santo Tomás de Aquino a la Ética (Catedral de Córdoba, Inc. 592) y los Comentarios de Leonardo Bruni a la Política (Catedral de Córdoba, Inc. 384). Por último, conviene también reseñar los comentarios a obras aristotélicas en griego, lo que remite a la moda humanista y a la preocupación por el acceso a

\footnotetext{
21. Idem, pp. 65-66.

22. García y García, Antonio et alii: Catálogo de los manuscritos e incunables de la catedral de Córdoba. Salamanca, Universidad Pontificia, Monte de Piedad y Caja de Ahorros de Córdoba, 1976.

23. Idem, pp. 71-72.
} 
la lengua original del Filósofo. Entre estos, sin embargo, no se encuentra ningún testimonio de la Ética. ${ }^{24}$

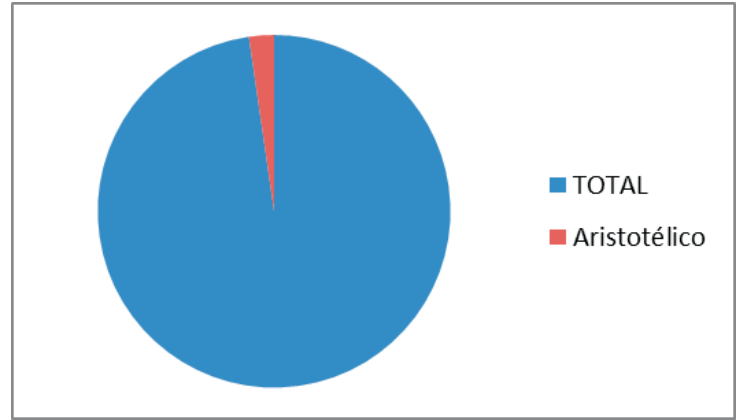

FIGURA 4. TOTAL DE MANUSCRITOS ARISTOTÉLICOS EN LA CATEDRAL DE CÓRDOBA. (Elaboración propia).

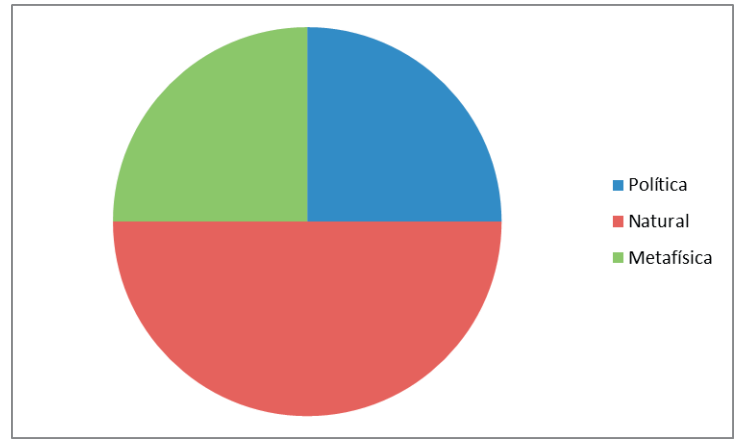

FIGURA 5. MANUSCRITOS ARISTOTÉLICOS EN LA CATEDRAL DE CÓRDOBA. (Elaboración propia).

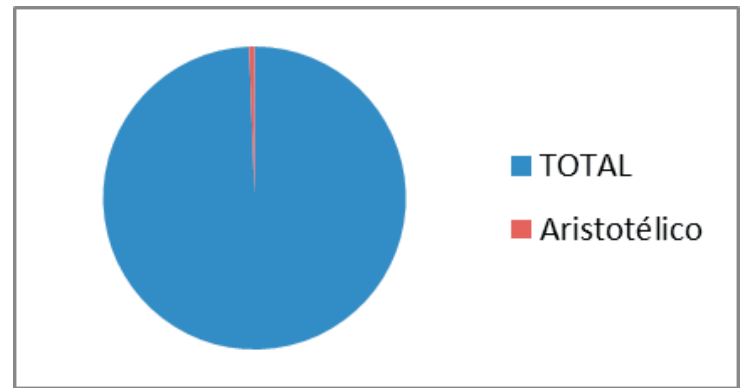

FIGURA 6. CORPUS ARISTOTÉLICO EN EL CONJUNTO DE INCUNABLES DE LA BIBLIOTECA DE LA CATEDRAL DE CÓRDOBA. (Elaboración propia).

24. Aristoteles, Opera (graece) Catedral de Córdoba, Inc. 436 (contiene obras de Filosofía natural); Aristoteles, Opera (graece), Catedral de Córdoba Inc. 591 (contiene la Física); y Aristóteles, Opera (graece), Catedral de Córdoba, Inc. 597 (contiene la Lógica y la Metafísica). 


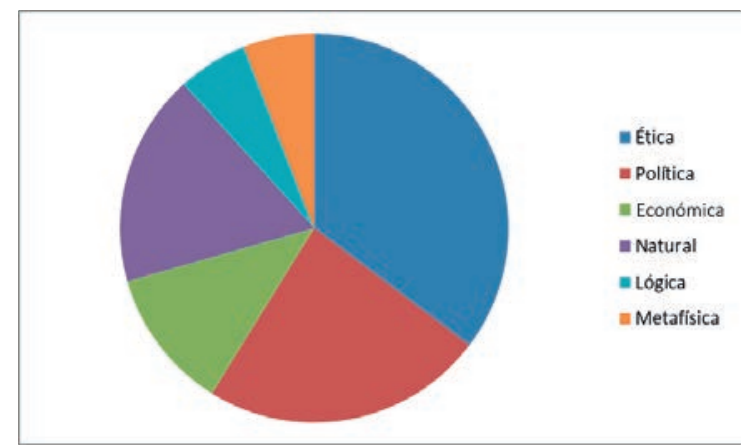

FIGURA 7. OBRAS ARISTOTÉLICAS EN LOS INCUNABLES DE INCUNABLES DE LA BIBLIOTECA DE LA CATEDRAL DE CÓRDOBA. (Elaboración propia).

En segundo lugar, el valor que se otorgaba al libro y a las bibliotecas en Sevilla queda constatado hasta el siglo XV en la biblioteca capitular. En el siglo siguiente este interés cultural seguiría creciendo con la fundación de la universidad (I502) y a través de la importante labor de Hernando Colón, manifestada en la donación que hizo a la ahora conocida como biblioteca colombina. Antes, la biblioteca del cabildo refleja una intervención regia de Alfonso X el Sabio, quien legó ejemplares muy valiosos a la catedral. ${ }^{25}$ Otro de sus donantes fue don Pedro de Gudiel y Barroso, quien en 1387 cedió i2o volúmenes de materia variada (Teología, Filosofía, Derecho, Patrística, Medicina y de obras de clásicos griegos y latinos). ${ }^{26}$ En el siglo XV la biblioteca se enriquece con la donación de Juan de Cervantes, cardenal de Ostia en I450, de 306 volúmenes, fundamentalmente de materia eclesiástica. En I473, Gonzalo Sánchez de Córdoba, arcediano de Jerez y canónigo de Sevilla, legará a la biblioteca de la catedral 63 volúmenes. ${ }^{27}$ Con razón, Sevilla es considerada la cuarta de España en riqueza de manuscritos.

De los io ejemplares que contienen la obra aristotélica, 8 son manuscritos. De los cuales, tres contienen la Ética: uno según el comentario de Alberto Magno (Sevilla, SE-CAT Capitular, 56-2-I2), ${ }^{28}$ otro según la versión de Leonardo Bruni (Sevilla, SECAT Capitular, 58-I-30), fechados los dos en el siglo XV y el tercero, fechado entre los siglos XIII y XIV, se corresponde con la versión de Eustracio de Nicea (Sevilla, SE-CAT Capitular, 56-2-I2). El cuarto de los ejemplares contiene los comentarios de Alberto Magno a la Política aristotélica (Sevilla, SE-CAT Capitular, 57-2-I4) y los

25. En 1284 ordena: 'Otrossy mandamos que todas las vestimentas de la nuestra capilla con todos los otros libros que los den a la yglesia mayor de Santa María de Sevilla...; otrosy mandamos que todos los libros de los cantares de loor de Santa María sean todos en aquella yglesia do el nuestro cuerpo se enterrare e que los fagan cantar en las fiestas de Santa María' (Archivo de la Catedral de Sevilla) (GuIllén TorRALBA, Juan: «La biblioteca de la Catedral. La Colombina», en La Biblioteca Colombina y Capitular. Sevilla, Consejería de Cultura y Medio Ambiente. Junta de Andalucía. Asesoría Quinto Centenario, 1990, 5-8, p. 5).

26. Guillén TORRALBA, Juan: «La biblioteca de la Catedral...», p. 7.

27. Idem, pp. 5-8

28. Y que perteneció al cardenal don Juan de Cervantes ( $\left.c^{a} 1380-1453\right)$. 
restantes contienen materias de Filosofía natural, Metafísica y Lógica ${ }^{29}$. En cuanto a los dos incunables que contienen la Ética, uno se trata del comentario de Pedro de Osma, ejemplar impreso en Salamanca en I496 (Sevilla, SE-CAT Capitular, 8II-2) y el otro, impreso en Venecia en I489, contiene los comentarios de Averroes y de Leonardo Bruni (Sevilla, SE-CAT Capitular, 68-2-I/2).

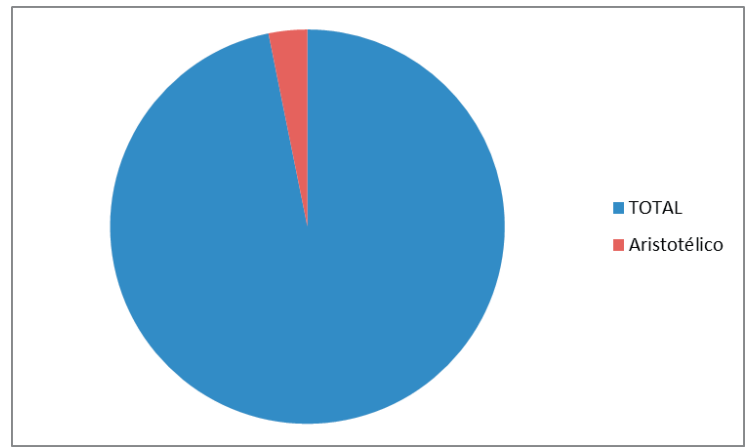

FIGURA 8. CORPUS ARISTOTÉLICO EN LA BIBLIOTECA DEL CABILDO SEVILLANO. (Elaboración propia).

Cuantitativamente, la representación aristotélica era escasa en comparación con el resto de volúmenes de la biblioteca. Además, la biblioteca de la catedral de Sevilla no conservaba ningún ejemplar de los comentarios tomistas y sin embargo sí de la versión de Leonardo Bruni y de Pedro de Osma. Estos dos autores son reflejo de los distintos derroteros de las corrientes humanistas, al mismo tiempo que demuestran cómo estas tradiciones no eran totalmente independientes, para lo que sirve de ejemplo el hecho de que la versión de la Ética que realizó Leonardo Bruni, que se ha calificado de aristocrática, fue la que Pedro de Osma empleó para escribir su comentario en un contexto universitario.

Hasta aquí, se puede corroborar que Burgos, Palencia y Salamanca eran los centros catedralicios más importantes en el alto Medievo. Los datos recogidos a partir de los inventarios señalan que, aunque se conserva documentación de bibliotecas catedralicias castellanas en el siglo XIII, será a partir del siglo XV cuando esta información resulte más completa..$^{30}$ Los criterios de la selección de las materias más predominantes, como ya es sabido, se rigen por intereses pedagógicos de carácter teológico y, sobre todo, orientados a la formación litúrgica. ${ }^{3 \mathrm{I}}$ Será en el Cuatrocientos cuando la representación aristotélica sea un poco más visible. Y, aunque no son numerosos los testimonios, no son tampoco inexistentes, lo que

29. Sevilla, SE-CAT Capitular, 56-6-19; Sevilla, SE-CAT Capitular, 57-2-16; Sevilla, SE-CAT Capitular, 56-1-27; Sevilla, SE-CAT Capitular, 125-3-30.

30. Guijarro González, Susana: Maestros, escuelas y libros..., pp. 133-137 y 164-166.

31. Resulta útil al respecto confrontar el «esbozo del perfil académico medio del clero cardenalicio castellano» que ofrece Susana Guijarro González (GuIJARRo GonzÁLEz, Susana: Maestros, escuelas y libros..., pp. 117-119). 
remite a un criterio selectivo que no parece completamente ajeno al desarrollo intelectual posterior.

\section{LA UNIVERSIDAD EN CASTILLA Y SUS BIBLIOTECAS}

La formación del clero desembocó en una ampliación de sus funciones sociales. El interés por una mayor unidad en la cristiandad contribuyó también al proceso de centralización de los estudios universitarios. ${ }^{32}$ En la Península Ibérica las primeras universidades surgieron como evolución de los primigenios Estudios Particulares, una vez hubieron obtenido el grado de Estudios generales y no dejando de guardar conexión con los centros catedralicios. Las concesiones de Estudio particular a General se hacían a través del rey (studia generalia respectu regni), quien solicitaba la licencia ius ubique docendi al papa. Esta conexión y confianza que el primado de Roma otorgaba a los reyes de Castilla influyó en la configuración de los programas de estudio, contenidos y actividades que se producían en las aulas universitarias y que seguían los modelos parisinos. La necesidad de contar con personal administrativo para el aparato cortesano-estatal aumentó la demanda para estudio de Leyes, para lo que la universidad castellana siguió un esquema similar al de la universidad de Bolonia, caracterizada por la importancia del componente secular y civil en la orientación y organización de sus estudios.33

Por lo tanto, y siguiendo la tradición, la enseñanza se organizaba en cuatro facultades: Artes Liberales, Medicina, Derecho y Teología. De la misma manera, la materia de Filosofía se dividía en Lógica, Filosofía natural y Filosofía moral. En la primera quedaban asumidas la Gramática y Retórica, la Filosofía natural formaba parte del quadrivium y la Moral se subdividía en Ética, Economía y Política. De todas formas, y aunque la Filosofía irá cobrando mayor interés como disciplina autónoma en Castilla, no encontramos cátedras en Filosofía moral hasta el siglo XVI. ${ }^{34}$

32. Aguadé Nieto, Santiago: «Las universidades y la formación intelectual del clero castellano en la Edad Media», en Aguadé NiETo, Santiago (coord.): Universidad, cultura y sociedad en la Edad Media. Alcalá, Universidad, 1994, pp. 159-206, p. 167.

33. Rashdall, Hastings: The Universities of Europe in the Middle Ages. Oxford, Clarendon Press, 1936, pp. 64-65 y 89-94. Resultará de especial interés para la difusión de la moral aristotélica, el caso de la universidad de Salamanca, en cuyas aulas se forjan los letrados de la corte.

34. En España, hay que esperar hasta los Estatutos de 1561 para poder hablar de una cátedra autónoma en Filosofía moral (EsPERABÉ de ARTEAGA, Enrique: Historia pragmática e interna de la Universidad de Salamanca. Salamanca, Universidad de Salamanca, 1914, vol. 1, pp. 262-263. 


\subsection{EL ESTUDIO GENERAL DE PALENCIA (1208-1214)}

El Studium Generale de Palencia (I208-I209) es el primer centro de carácter universitario fundado en la península ibérica. Hay varias discusiones acerca del tipo de autoridad sobre la que se fundó este centro. Me inclino por aquella que defiende que, aunque se creara bajo el amparo del rey Alfonso VIII (II58-I2I4), la verdadera promoción del Studium fue de carácter eclesiástico, igual que el resto de Studia europeos que se estaban desarrollando en este período. El monarca no influía directamente en su promoción aunque sí que contribuía a ella, como veremos. Otra cuestión es que algunos cronistas consideraran oportuno (u oportunista) transmitir una imagen de un rey promotor de cultura y sabiduría en su reino. ${ }^{35}$ En II78, el monarca Alfonso VIII de Castilla reconoció este Estudio, basándose en la ya existente escuela catedralicia. ${ }^{6}$ Sin embargo, la trayectoria del Estudio se ve afectada por la muerte de Alfonso VIII en I2I4. Son significativas para el Estudio las figuras del obispo don Raimundo de Toledo (II48-II83) y don Tello Téllez de Meneses (ca. II70-I246). Aunque este último trabajó en su promoción y mantenimiento y el rey Fernando III (I2I7-I252) logró algunos privilegios del papado, nunca se consiguieron bulas de fundación. Tras el sínodo de Valladolid de 1228 se lograron otros privilegios. ${ }^{37}$ Pero a fines del siglo, en I263, este estudio había desaparecido. ${ }^{38}$

Este centro se caracterizará por poseer un carácter teológico más que jurídico; se enseñaba Teología, Leyes canónicas (contando con profesorado italiano), además de Lógica y Gramática. El número de ejemplares que contenía la biblioteca del cabildo palentino era de 332. Casi la mitad de ellos estaban destinados a la celebración de actos litúrgicos, pero todos, excepto un ejemplar, han desaparecido. Como la razón principal de esta institución era la formación en Teología,

35. Fuente Pérez, María Jesús: «El nacimiento de la universidad de Palencia en el contexto de las universidades europeas», en Fuente Pérez, María Jesús (coord.): El estudio general de Palencia. Historia de los ocho siglos de la Universidad española. Valladolid, Universidad de Valladolid, 2012, pp. 69-89, pp. 74-75.

36. Rashdall, Hastings: The Universities of Europe..., p. 66 y Martínez Díez, Gonzalo: «Palencia, la primera universidad de España», en Torremocha Hernández, Margarita (coord.): El Estudio General de Palencia. Historia de los ocho siglos de la universidad española. Valladolid, Universidad de Valladolid, 2012, pp. 47-68, p. 46. Aunque hay que matizar las palabras de Gonzalo Martínez Díez cuando defiende que se registraban «abundancia de maestros presentes en el cabildo palatino» con el trabajo de María Jesús Fuente Pérez.

37. «El Studium de Palencia fue uno de los que -junto a París, Oxford y Bolonia- recibió misivas de Honorio III, Gregorio IX, Inocencio IV y Urbano IV. El apoyo de Honorio III en tres bulas de 1220, 1221 y 1225, [fue motivado] probablemente por el obispo Tello Téllez, que tenía fluida relación con el pontífice.[...E]n 1263 Urbano IV concediera a los doctores y escolares palentinos los mismos privilegios que a los parisinos fue un apoyo importantísimo, pero puede que no suficiente, para evitar su desaparición cuando no se la autorizaba a la enseñanza del Derecho, y tenía la competencia del recién creado Studium salmantino» (TORREMOCHA HERNÁNDEZ, Margarita: «Introducción», en El estudio general de Palencia....p. 11 y MARTínez DíEz, Gonzalo: «Palencia, la primera....», p. 61). Esta situación pone al Estudio General de Palencia al nivel de los demás Centros europeos que florecieron sobre todo a partir del siglo XII.

38. Margarita Torremocha Hernández menciona en el estudio citado las tres fases en la historia del Estudio de Palencia: la primera fase, la fundacional, comprende el período desde 1180-1275, aproximadamente, con el predominio region de Alfonso VIII. La segunda fase, de 1214 a 1246, con el Obispo don Tello Téllez de Meneses. Y la tercera fase en la que comienza su decadencia, una vez fallecidos su fundador en 1214 y su restaurador y patrocinador en 1246, hasta desaparecer aproximadamente hacia 1263 
son los libros de contenido bíblico y litúrgico los más abundantes. ${ }^{39}$ En la misma línea, en materia de leyes el inventario incluye libros de Derecho Canónico sobre todo. De los libros de Artes Liberales se incluye en el inventario una Gramática, el Papias Vocabulista. El cabildo se surtirá en el futuro de diversas donaciones, como la del arzobispo sevillano don Diego Hurtado de Mendoza (I444-I502), previamente obispo de Palencia entre I473-I485, o la del médico Luis Rodríguez de Pedrosa en 1505. En el siglo XVI destacan las donaciones del bachiller Juan de Ortega y el licenciado Gregorio del Castillo..$^{\circ}$ En la materia que aquí interesa, la de Filosofía moral, consta un Tractado de virtutibus de Guillermo de Perault. Por último, la representación aristotélica (directa e indirecta) y pseudo-aristotélica queda representada en las siguientes obras fechadas en el siglo XV: De regimine principum, otro titulado Sobre la metafísica de Aristóteles, de comentador desconocido, un libro de Filosofía moral, cuyo autor desconocemos, un pseudo-aristotélico sobre Filosofía (moral) y Medicina, de autor también desconocido y un De propietatibus animalium. ${ }^{4 \mathrm{I}}$

Además del número de ejemplares que pudieron conservarse en la biblioteca, hay que considerar el intercambio intelectual y librario que se produjo a través de la circulación internacional de profesores y estudiantes. Un claro reflejo de estas influencias recíprocas son las señaladas por María Jesús Fuente Pérez a propósito del Verbiginale, la gramática latina escrita para Tello Téllez de Meneses, en la que se incluye un verso del Alexandreis. ${ }^{42}$ A propósito de lo cual, conviene señalar la hipótesis de que fue al amparo de este centro palentino donde se formaría el supuesto autor del Libro de Alexandre, héroe (o anti-héroe) que recibió la educación del mismo Aristóteles y en el que se percibe la tendencia a la aplicación de unos conocimientos clericales en un ámbito cortesano. Esta última dirección terminará de forjarse y difundirse a partir del Estudio salmantino, donde la concesión papal de la licentia docendi para los estudios de Derecho influirá en su posicionamiento cultural y político en el reino castellano, así como en la evolución del discurso intelectual y político monárquico.

\subsection{EL ESTUDIO GENERAL DE VALLADOLID (SIGLO XIII)}

El Estudio particular de Valladolid existía desde I292, según consta en los privilegios económicos concedidos por Sancho IV (I284-I295). Estos se mantuvieron

39. $37 \%$ de libros de liturgia o de Sagradas Escrituras, $20 \%$ de teología, $17 \%$ de derecho canónico y un 3\% de derecho civil (Fuente, María Jesús: El Estudio General de Palencia. La primera universidad hispana. Palencia, Cálamo, 2012, p. 188). 40. Reyes Asenjo, Laura: Catálogo de los libros manuscritos de la biblioteca capitular de Palencia. Palencia, Institución Tello Téllez de Meneses, 2006, pp. 25-26.

41. Guijarro González, Susana: Maestros, escuelas y libros...., Anexo, ítem 1734, 1910, 1907, 1717 y 1916 respectivamente.

42. Fuente Pérez, María Jesús: «El nacimiento de la universidad...», p.87. 
a lo largo de los sucesivos reinados, confirmando el apoyo regio y la colaboración concejil para la distribución económica. ${ }^{43}$

Gracias al impulso regio, el núcleo escolástico surgido alrededor de la catedral de Santa María se convertiría en Estudio, al que el papa Clemente Vl, por petición del rey Alfonso XI (I33I-I350), otorgó el grado de Estudio General en la bula de I346. Seguía siendo privilegio exclusivo de la universidad de París la cátedra de Teología, hasta que el papa Martín V (I4I7-I43I) le otorgara a Valladolid el privilegio en I4I7 para enseñar también esta materia. Así que, hasta entonces, en el estudio vallisoletano se impartía Gramática, Aritmética, Latín y Sagrada Escritura. Las primeras cátedras que se erigieron fueron las de Prima Filosofía, Prima de Teología de las Partes de santo Tomás (I404-I405), aunque la confirmación pontificia no llegó hasta I4I8, y la de Filosofía natural (en I500). En el siglo XIV contaba con tres cátedras de Derecho canónico y dos de Leyes, y una más que se añade en el siglo XV. ${ }^{44}$ Hay que esperar hasta el siglo XVII y XVIII para encontrar una cátedra de Teología moral (primer intento en I68I y facultad real en I743). ${ }^{45}$

La biblioteca debió de existir desde la fundación de la universidad (I24I), pero no se le atribuyó tal nombre hasta que recibió los libros procedentes de la compañía de Jesús, que sería expulsada de España por Carlos III en el siglo XVIII. Más adelante se le añadieron los libros de las órdenes religiosas suprimidas. En I844 se estableció un local fijo para la biblioteca y en I860 se incorporó el cuerpo de bibliotecarios..$^{46}$ Por desgracia no contamos con un catálogo que nos informe de las obras que contenía la biblioteca antes del siglo XVI. ${ }^{47}$

Sí tenemos acceso a los datos de la biblioteca del Colegio de Santa Cruz, institución fundada en I483 por don Pedro González de Mendoza, arzobispo de Toledo desde I482. La tendencia a la formación burocrática se manifiesta también en la erección del colegio de san Bartolomé de Salamanca, que veremos más adelante.

43. Entrega de tercias por parte de Sancho IV, Alfonso XI en 1333 entrega 10.000 maravedís procedentes de las tercias del pan, vino y ganado, que debe arrendar el consejo de la ciudad, para pagar los salarios a los maestros. Fernando IV, en 1342, concedió 20.000 maravedís de los pechos y otras rentas del concejo de la villa y su tierra. En 1376 Enrique II confirma tales privilegios y exime a la universidad de todo pecho y tributo. Juan I ratificará estos privilegios (Del Val Valdivieso, María Isabel: «Universidad y oligarquía urbana en la Castilla Bajomedieval», en Aguadé Nieto, Santiago (coord.): Universidad, cultura y sociedad en la Edad Media. Alcalá, Universidad, 1994, pp. 133-146, pp. 135-136).

44. Guijarro González, Susana: Maestros, escuelas y libros...., p. 93.

45. Alcocer Martínez, Mariano: Historia de la Universidad de Valladolid. T.3, expedientes de provisiones de cátedras. Valladolid, Imprenta Castellana, 1921, pp. 41-62.

46. Gutiérrez del CAÑo, Marcelino: Códices y Manuscritos que se conservan en la Biblioteca de la Universidad de Valladolid. Valladolid, Universidad de Valladolid, 1988, p. iii.

47. Según el catálogo moderno, la biblioteca universitaria estaba formada de un total de casi 430 ejemplares entre manuscritos e incunables. La materia jurídica es de las más representadas, sobre todo desde el establecimiento de la chancillería en 1480. De materia aristotélica se puede unicamente reseñar, según los intereses de este trabajo, la existencia de un ejemplar manuscrito de la traducción de Juan García de Castrojeriz del De regimine principum de Gil de Roma (Valladolid, Universidad, Ms.251). De entre los incunables raros, 16 son de obras aristotélicas, predominando de nuevo las materias de Lógica, Filosofía natural y Metafísica. La Filosofía moral aristotélica queda representada en los tres incunables: uno contiene la versión de Averroes, junto con otras materias de la filosofía aristotélica (Valladolid, Universidad, Inc. 11, 12, 13), otro el comentario de la Ética por Gerardo de Odón (Valladolid, Universidad, Inc. 36 y 37 ) y el tercero la de Juan Versor (Valladolid, Universidad, Inc. 98). 
Junto al Colegio de Santa Cruz, estos centros de estudio se orientaban, en principio, a la educación de aquellos que 'por falta de recursos no podían dedicar las agudas facultades a las letras'. La realidad, sin embargo, acabó convirtiéndolos en medios de formación de la burocracia urbana con 'tendencia a crear castas hereditarias de extraordinaria fuerza social'. ${ }^{8} \mathrm{Al}$ revisar su catálogo, se registra una obra aristotélica fechada en el siglo XV (De animalibus, según la versión de Jorge de Trebisonda). ${ }^{49}$ El resto de ejemplares aristotélicos (7) son todos del siglo XVI y XVII y ninguno contiene la Filosofía moral.50

\subsection{EL ESTUDIO SALMANTINO}

El rey Alfonso IX (II88-I230) instituyó el Estudio de Salamanca alrededor del año I2I8. Su hijo Fernando III (I2I7-I252/I230-I252) continuó esta labor y Alfonso X el Sabio (I252-I284) estableció los estatutos en I254. Un año más tarde, el 2 de junio, el papa Alejandro IV le otorga sello propio y unos meses después, el 22 de septiembre, la codiciada licentia ubique docendi (exceptuando la de Teología, reservada a la universidad de París, y la de Leyes, reservada a Bolonia). El Estudio había aumentado el número de estudiantes y profesores extranjeros; son ejemplos conocidos el del italiano Marineo Sículo (I484-I496) y Arias Barbosa, formado en Italia (I470-I540). El ambiente de recepción de los clásicos y la preocupación por los studia humanitatis queda reflejado en la labor de la denominada Primera Escuela de Salamanca (donde Alfonso Fernández de Madrigal, el Tostado, Pedro de Osma y sus discípulos son representantes de la corriente humanista hispánica que se gesta en el terreno salmantino); otro signo de esta realidad será la fundación de la cátedra de Retórica (27 de abril de 1509).5

A la influencia de la Corona en el desarrollo del Estudio salmantino, se añade el apoyo pontificio, la decadencia (económica e intelectual) del palentino y los intercambios internacionales entre profesores y estudiantes con las otras universidades europeas (fundamentalmente París y Bolonia). Estos factores influyeron para que el foco de intelectualidad castellana se trasladara a Salamanca donde, además, la corte y el aparato burocrático tendrían su domicilio durante largas

48. Conviene anotar que el término 'burocracia' no se registra, tal y como lo entendemos ahora, hasta el siglo XIX. Pero el concepto sí puede aplicarse a la evolución y la organización en la estructura de las funciones de las cortes tardomedievales y renacentistas (NIETO SORIA, José Manuel: «Prólogo», en CAÑAS GÁlVEZ, Francisco de Paula: Burocracia y cancillería en la corte de Juan II de Castilla ...

49. Valladolid, Universidad. Mss. 142.

50. Uno de los trabajos que estudia la biblioteca en el siglo XVI es el de SOBALER SECO, María Ángeles: «Tiempo y espacio de la lectura en los colegios mayores castellanos. Los libros del colegio de Santa Cruz de Valladolid en el siglo XVI», en García, Máximo y Sobaler, Ma Ángeles: Estudios en homenaje al profesor Teófanes Egido. Valladolid, 2004, pp.309-332.

51. Beltrán de Heredia, Vicente: Cartulario de la Universidad de Salamanca (1218-1600). Salamanca, Universidad, 1970, vol. 3, p. 549 . 
temporadas..$^{52}$ Esto explica también que la organización de los estudios se fundamentara especialmente en los jurídicos. Ya bajo Alfonso X había dos cátedras de Derecho civil, tres para Derecho canónico, dos para Lógica, dos para la facultad de Artes y una para Medicina. En el siglo XIV, el Decreto de Clemente VII (I523-I534) del 9 de agosto de 1393 aumenta el número de las cátedras en dos para Derecho civil y cuatro para Decretales. La facultad de Teología no comenzó a funcionar hasta I38I-I386, dada la centralización de esta materia en París; pero entonces el papado podía confiar en la ortodoxia castellana, que fue corroborada por el apoyo que la universidad prestó a la causa de Benedicto XIII (I375-I4I5) y sobre todo cuando sus relaciones con Avignon eran especialmente tirantes (I395-I396). En esta facultad de Teología se formaron Juan de Segovia (†I458) y Alfonso Fernández de Madrigal, el Tostado (I40o-I455), que tuvieron un papel relevante en el escenario conciliar de la Iglesia y cuyas obras influyeron en la recepción aristotélica castellana. La obra de Pedro Martínez de Osma (I427-I480) y de sus discípulos completará el cuadro de las tradiciones a través de las cuales se difundió la moral aristotélica desde el contexto salmantino.

\subsubsection{Biblioteca catedralicia y la donación del obispo don Gonzalo Vivero (1480)}

Durante los siglos XIII y XIV la biblioteca de la catedral de Salamanca contenía libros de Teología, escritos de los Padres de la Iglesia y, como representación de los clásicos, obras de Salustio y las Bucólicas de Virgilio. En el siglo XV, gracias a la importante donación del obispo de Salamanca don Gonzalo Vivero (I442-I480), la biblioteca de la catedral aumenta considerablemente sus fondos. Florencio Marcos Rodríguez, a partir de la lectura del testamento otorgado por el obispo el 27 de enero de I480, afirma que tal documento 'nos revela al amante de las ciencias: Teología, Derecho, Agricultura, Nigromancia, etc., tampoco faltan detalles de un apasionado del arte, como un cabal renacentista, según nos lo demuestra la siguiente cláusula.53 El conjunto es estimado económicamente en 200.000 maravedís, lo que corrobora la importancia cuantitativa y cualitativa de la misma. Este investigador extrae el contenido de la biblioteca a partir del análisis y estudio del inventario de la biblioteca de 1533 (750 volúmenes). Para deducir el número de libros que contendría, y que equivaldría a la donación que hizo el

52. Durante los años 1432-1433, los días 14 y 15 de enero de 1440 a propósito del acompañamiento a los miembros de la Audiencia Real o en 1441, junto a la Chanchillería Real (SÁNCHEZ SÁnCHEZ, Daniel: «Catedral y Universidad, una relación secular», en Historia de la Universidad de Salamanca I. Trayectoria y vinculaciones. Salamanca, Ediciones Universidad de Salamanca, 2002, 405-434, p. 408 y CAÑAS GÁLVEZ, Francisco de Paula: Burocracia y cancillería en la corte de Juan II de Castilla...).

53. Marcos Rodríguez, Florencio: «La antigua biblioteca de la catedral de Salamanca», Hispania Sacra, 14 (1961), pp. 281-319, p. 289. 
obispo don Gonzalo de Vivero antes de que se hiciera tal inventario, propone el siguiente cómputo: descontar los códices del inventario de I275 (I6 ejemplares), los libros que figuran en el inventario de I5Io de Juan de Castilla (325 obras) y las obras posteriores a I480 (fecha de la muerte de don Gonzalo). De esta manera, y aunque no ha sido posible identificar todas las obras, sí puede deducirse que el total de ejemplares que contenía la biblioteca debía de ser considerable, dadas las dimensiones de la capilla de santa Catalina (donde se guardaban los libros) y la importancia que otorgaba el obispo don Gonzalo a su biblioteca. ${ }^{54}$ De entre los datos que se conservan, aun no siendo definitivos por la falta de información completa (tanto de cantidad como cronológica), y recogidos a partir del inventario de I533, se puede extraer también una idea del corpus aristotélico: de las 20 de las obras aristotélicas que recoge el inventario de 1533,5 se corresponden con la materia de Filosofía moral. Es interesante remarcar en este sentido que la donación a cargo de Gonzalo Vivero reúne un buen rango de traducciones y comentarios: el de Juan Versor, Super ethica et politica, el del maestro Osiri, Lectura super ethica magistri Osiri, el de Walter Burley, Super libros ethicorum et polit, el de Tomás de Aquino, Super ethica y la traducción de Leonardo Bruni, Ethica et política et oeconomica. De las obras pseudo-Aristotélicas, la biblioteca contenía un ejemplar del Secretum secretorum. Por último, también se citan el regimiento de príncipes de santo Tomás de Aquino, otro que se corresponde con el de Gil de Roma y un tercero de quien no se especifica autor. ${ }^{55}$

\subsubsection{La biblioteca de la universidad}

El libro era un producto caro, al que solo algunos afortunados podían acceder. Se hacía cada vez más urgente paliar la necesidad con una biblioteca universitaria. El papa Benedicto XIII se dedicó a este proyecto, haciendo posible que se adquiriesen los autores más imprescindibles. Así, a base de compras y donaciones, la biblioteca fue formándose y creciendo a lo largo del siglo XV. Vicente Beltrán Fernández de Heredia recoge los testimonios que dan fe de esta actividad bibliotecaria: en I467 se entrega una partida de libros; un año después se registran dos órdenes de compra de libros; en I470 se encomienda a Pedro de Osma y al doctor Diego Rodríguez de San Isidro revisar los ejemplares del monasterio de San Francisco

54. Ibidem

55. Además de las obras más directamente relacionadas con la Moral, se citan en el inventario los siguientes títulos aristotélicos: Opera Aristotelis, Sanctus Thomas super libros de anima, Rethorica Aristtoelis, Metaphysica Aristotelis et alia, Aritoteles de animalibus, Lectura beati Thomae super physica, Gil Romanus. Super physica, Gil Romanus. Super de anima, Rethoria de Gil Romano, Glossa super de animalibus, Logica Aristotelis, Gil Romanus sobre los Posteriores y Logica et alia opera. Se incluye también una obra con el título Translatio antiqua que quizá pudiera referirse a la versión de Grosseteste de la Moral. (Marcos Rodríguez, Florencio: «La antigua biblioteca de la catedral de Salamanca»... y Aguadé Nieto, Santiago: Libro y cultura italianos en la Corona de Castilla durante la Edad Media, Alcalá de Henares, Universidad de Alcalá, 1992. 
que pudiera interesar tener en la biblioteca universitaria; desde 1467 consta que el rector y maestrescuela habían acordado el horario de apertura del edificio (dos horas por la mañana y hora y media por la tarde); en I47I la biblioteca ya está en orden y funcionamiento.

La información sobre el fondo antiguo remite a un conjunto de manuscritos conservados con la antigua indicación de 'Es de la Universidad de Salamanca'; a esos podrían añadirse los que conservan hierros para cadenas o sus huellas (que pertenecerían a la donación de Juan de Segovia) y los que constituyeron la donación de Alfonso Ortiz. ${ }^{56}$ En relación al volumen de la biblioteca de la universidad, contamos con el testimonio de la visita de mayo de I47I, donde se registran 200 volúmenes anotados en el libro del bedel Valdivieso. De ese conjunto quedan fuera de cómputo los donados por Juan de Segovia (ca.1393-I458), quien ordenó que se guardaran en el arca y no fueran accesibles al público. En julio de 1472 está recogida la donación del doctor Gonzalo Méndez, catedrático jubilado de Decretales, que legó a la universidad libros de su especialidad. En agosto de ese mismo año, el maestro Pascual Ruiz, que se encargaba de la ordenación de la librería junto con el bachiller Quintanilla, colocaron 'en una banca cabe la arca entrando a mano izquierda un Versorio sobre toda la Filosofía moral [aristotélica] e un Versorio todo el texto de los de Generatione, con otros libros de medicina de autores árabes y el Buridán sobre los físicos'. Con la llegada de la imprenta, la adquisición de libros fue más copiosa y se llega hasta los 1.480 registros de ejemplares. ${ }^{57}$

\subsubsection{Donación de Juan de Segovia (1457)}

Para la información de los ejemplares de este teólogo y maestro contamos con el documento de la donación de libros hecha en favor de la Universidad salmantina y que terminó de redactar en 1457 (Salamanca, Universidad, Ms. 2II). En este documento se recoge un total de 73 ejemplares. Tal donación demuestra su amor por los libros -no quería que se desperdigaran ni se perdieran -y su deseo de que se conociera a Dios y se defendiera la fe.$^{5}$ Esto explica que la materia teológica sea la predominante. Julio González afirma que estos libros procederían de Italia, traídos por familiares o amigos. Entre las obras también se registran algunas aristotélicas: la Metafísica [Salamanca, Universidad, Inventario, 79];59 dos ejemplares

56. Lilao Franca, Oscar y Castrillo González, Carmen (eds.): Catálogo de Manuscritos de la Biblioteca Universitaria de Salamanca. Salamanca, Universidad, 1997, p. 14.

57. La Universidad parecía haberse contagiado del afán que por entonces dominaba a los humanistas italianos por acrecentar sus tesoros bibliográficos, instalándolos en local propio con toda magnificencia. Tratándose de la biblioteca no reparaban en gastos. (BELTRÁN de HeREDIA, Vicente: Cartulario de la Universidad de Salamanca... p. 207.

58. Antelo IglesiAs, Antonio: «Las bibliotecas del otoño medieval. Con especial referencia a las de Castilla en el siglo XV», Espacio, Tiempo y Forma, Serie 3, Historia Medieval, 4 (1991), pp. 285-350, pp. 325-326.

59. Sequuntur libri aliarum scienciarum theologie famulancium: Metaphisica Aristotelis secundum antiquam translationem in quo libro Tullius Tusculanarum Disputationum immo quinque et in fine Logica viridiam. (HERNÁNDEZ 
de la Ethica [Salamanca, Universidad, Inventario, 82 ${ }^{60}$ y [Salamanca, Universidad, Inventario, 83]; Liber de bona fortuna [Salamanca, Universidad, Inventario, 82]; y las Politicae, Magnorum Moralium, Rethoricorum et Yconomicorum y Poeticorum [Salamanca, Universidad, Inventario, 83].

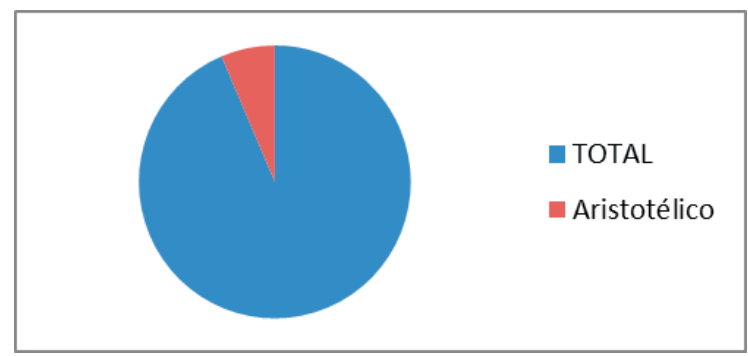

FIGURA 9. TOTAL DEL CORPUS ARISTOTÉLICO EN LA BIBLIOTECA DE JUAN DE SEGOVIA. (Elaboración propia).

La presencia de los clásicos queda constatada en las obras de Boecio (De disciplina scholarium y De consolatione), Cicerón (las dos Retoricas, Paradoxiae y Tusculanorum Disputationes IIII), Prisciano, Séneca (Liber epistolarum, De Naturalibus, De Ira y Flores omnium librorum) y Tito Livio (Décadas). Aunque domina el volumen de obras de interés teológico (documentos conciliares y dogmáticos en gran mayoría).

Julio González defiende que la biblioteca de Juan de Segovia, contando con la escasez de medios del teólogo, no tenía mucho que envidiar a las otras bibliotecas contemporáneas (la Biblioteca Vaticana, la de los Médicis, Nicoli de Florencia, Visconti, Besarion o Federico de Urbino).

\subsubsection{Manuscritos con procedencia explícita de la biblioteca universitaria}

De los 17 manuscritos de fondo antiguo, 5 son de materia aristotélica. Ninguno pertenece a la Filosofía moral y abundan los de Filosofía natural: la obra de Jorge de Trebisonda, traducida al latín por Alonso de Palencia, Libri de comparatione philosophorum Platonis et Aristotelis. Protectio Aristotelis Problematum (Salamanca, BUS, Ms.95). Otro recoge la traducción de Trebisonda de la Rhetorica, cuyo

\footnotetext{
Montes, Benigno: Biblioteca de Juan de Segovia: Edición y comentario de escritura de donación (coll. Bibliotheca theologica hispana, ser. $2^{\text {a }}$, t. 3. Madrid, CSIC, 1984).

6o. Liber Ethicorum Aristotelis secundum tres translaciones et in principio comentum Francisci de Mediolani; quamuis non sermonis exponentis aperientis tamen textus intencionem. Item yconomica existimata Aristotelis et Liber de Bona Fortuna. Sabemos que Juan de Segovia da el nombre de translatio nova a la de Leonardo Bruni, antiqua a la de Roberto Grosseteste, y sobre la referencia de la translatio media puede haber varias posibilidades: bien puede referirse a la versión de Guillermo de Moerbeke o a la de Juan Argyropulos. (Idem, p. 83).

61. Omnes Textus, preter libros Ethice, Aristotelis, de Philosophia morali, videlicet: Politicae, Magnorum Moralium, Rethoricorum et Yconomicorum, poeticorum, et in eo Tulios et Paradoxie [Paradoxae Stoicorum de Cicerón] et Boetius de Disciplina scolarium. (Ibidem).
} 
poseedor fue el mismo Alonso de Palencia (Salamanca, BUS, Ms. 63), los otros tres contienen obras de Filosofía natural aristotélica en las traducciones de Trebisonda (De anima, Physica y De generatione et corruptione) (Salamanca, Universidad, Ms. 68), las traducciones de Boecio de los Priora analytica, Topica, Sophistici elenchi (Salamanca, BUS, Ms. II6) y las de lacobus de Posteriora analytica y (Salamanca, BUS, Ms. II7).

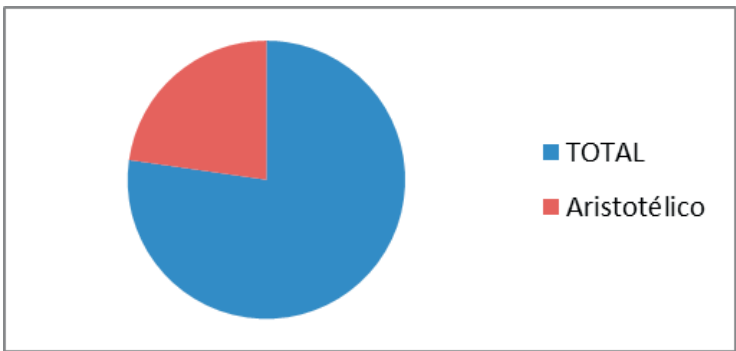

FIGURA 10. CORPUS ARISTOTÉLICO EN EL FONDO ANTIGUO DE LA BIBLIOTECA UNIVERSITARIA DE SALAMANCA. (Elaboración propia).

\subsubsection{Bibliotecas de los colegios universitarios de san Clemente y de san Bartolomé}

En la medida en que las bibliotecas de los colegios universitarios creados en el siglo XV también aportan información sobre los fondos librarios y el contexto intelectual originado en, y a través de, la universidad salmantina, recojo aquí los datos relevantes para el estudio de los inventarios de la biblioteca del colegio de San Bartolomé y, en Roma, del colegio de españoles de San Clemente.

\section{Colegio de san Clemente: Real Colegio de España en Bolonia (1364)}

Este Colegio debe su prestigio a la actividad de don Gil de Albornoz (I295-I367), quien donó a su biblioteca sus 36 volúmenes. ${ }^{62}$ De entre ellos, 8 corresponden a manuscritos aristotélicos, de los cuales 2 son de la Ética: uno contiene la versión latina de Grosseteste (siglo XIII), Liber Ethicorum iuxta versionem Roberti Grosseteste. Metaphysica (Collegio di Spagna, Ms. I63) y otro los Comentarios de santo Tomás, In decem libros Ethicorum expositio (siglo XIV-XV) (Collegio di Spagna, Ms. 267). A estos se añade la representación de obra moral pseudo-aristotélica en el ejemplar del De bona fortuna (siglo XIII) (Collegio di Spagna, Ms. I6I). De entre los incunables, cinco son de obras aristotélicas y ninguno pertenece a la Ética. ${ }^{63}$

62. García y García, Antonio et alii: Catálogo de los manuscritos e incunables de la catedral de Córdoba...

63. Estos son los incunables registrados en el catálogo recogido por Ferdinando Rodríguez: Albertus de Saxonia, Quaestiones in libros Aristotelis de caelo et mundo, Venezia, Boneto Locatello, ed. Ottaviano Scoto, 24. Oct. 1492 (Bologna, 


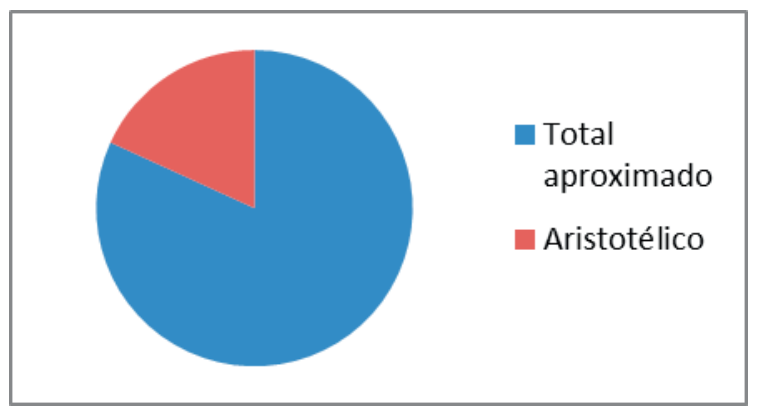

FIGURA 11. CORPUS ARISTOTÉLICO Y REPRESENTACIÓN DE LA ÉTICA ARISTOTÉLICA EN LA BIBLIOTECA DEL CARDENAL GIL DE ALBORNOZ. (Elaboración propia).

\section{Colegio de san Bartolomé (1401)}

La biblioteca del Colegio de san Bartolomé debe mucho al celo de don Diego de Anaya y Maldonado (I367-I437), obispo de Salamanca, promovido en I408 a la diócesis de Cuenca y en I4I8 a la de Sevilla, quien contribuyó a formar la biblioteca del colegio, dotándola, en I437, de la colección que había ido reuniendo a lo largo de sus estancias en Italia -donde tomaría como modelo para el suyo el colegio de Bolonia a su vuelta del concilio de Constanza (I4I7). ${ }^{64}$

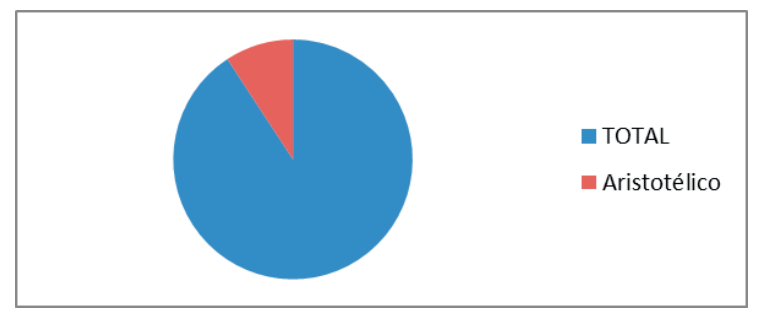

FIGURA 12. TOTAL DEL CORPUS ARISTOTÉLICO EN LA BIBLIOTECA DEL COLEGIO DE SAN BARTOLOMÉ. (Elaboración propia).

La mayoría de los 472 volúmenes que forman la donación son de contenido científico. ${ }^{65}$ De entre ellos, 48 se corresponden con obras de carácter aristotélico.

Colegio di Spagna, H.IV. $\left.7^{2}\right)$; Antonius Andreas, Scriptum in artem veterem Aristotelis et in Divisionem Boethii, Venezia, Ottaviano Scoto, 24. Dic. 1480 (H.IV.9); Aristotele, Opera [in latino], Comm. Averroes, Venezia, Bernardo Stagnno, 15. Feb-etc. 1489 (G.II.2); Escotus, Quaestines in Metaphysicam Aristotelis: De primo rerum principio tractatus; Theormata y Maritius de Portu Hibernae, Epistomata, Venezia, Boneto Locatello, ed. Ottaviano Scoto, 20. Nov. 1497 (G.III.92); Jacobus de Voragine, Quaestiones super Physicam Aristoelis, Venezia, Boneto Locatello, ed. Ottaviano Scoto, 7. Feb. 1492 (G.VI.5). (Rodríguez, Ferdinando: Catálogo degli Incunaboli della Biblioteca del Colegio di Spagna a Bologna. Bolonia, Real Colegio de España en Bolonia, 1972, vol. 2, pp. 699-712).

64. Galende Díaz, Juan Carlos: «La biblioteca del Colegio Mayor salmantino de san Bartolomé en el siglo XVIII», Revista General de Información y Documentación, Vol. $10: 2$ (2000), pp. 33-69, p. 35, disponible en <http://revistas.ucm. es/index.php/RGID/article/view/RGIDoooo220033A> [acceso 15 noviembre 2017].

65. Aguadé Nieto, Santiago: Libro y cultura italianos en la Corona de Castilla..., pp. 110-111. 


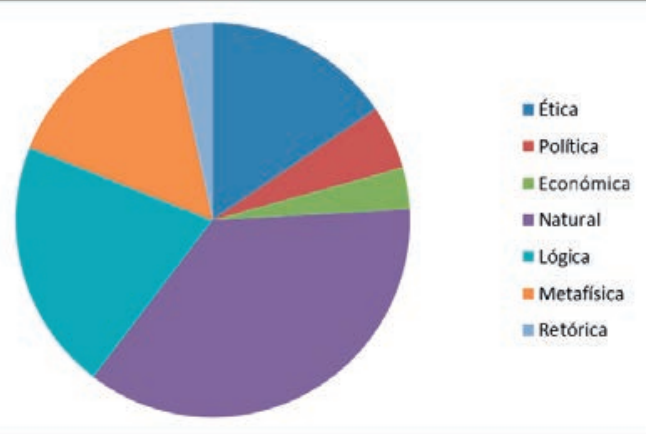

FIGURA 13. REPRESENTACIÓN DE EJEMPLARES DE LA ÉTICA EN EL CORPUS ARISTOTÉLICO EN LA BIBLIOTECA DEL COLEGIO DE SAN BARTOLOMÉ. (Elaboración propia).

Abundan los ejemplares referentes a Filosofía natural y les sigue en prioridad los de Lógica. Las siguientes materias, en orden de cantidad, son la Metafísica y la Ética. De esta última localizamos 8 ejemplares: Magna Moralia, Ethica Eudemia y la versión de la Ética de Grosseteste (Salamanca, BUS, Ms. 2705), los comentarios tomistas (Salamanca, BUS, Ms. 2259), la versión de Gerardo de Odón (Salamanca, BUS, Ms. I869), la de Pedro de Corveheda (Salamanca, BUS, Ms. 2423), la traducción de la Ética, Política y Económica Leonardo Bruni (Salamanca, BUS, Ms. 2603 y uno que incluye los comentarios de Pedro de Osma (Salamanca, BUS, Ms. 2604).

Una vez reunidos todos los datos, si hiciéramos un cómputo visual del total de representación de ejemplares de materia aristotélica en el ámbito universitario salmantino, quedaría representado así:

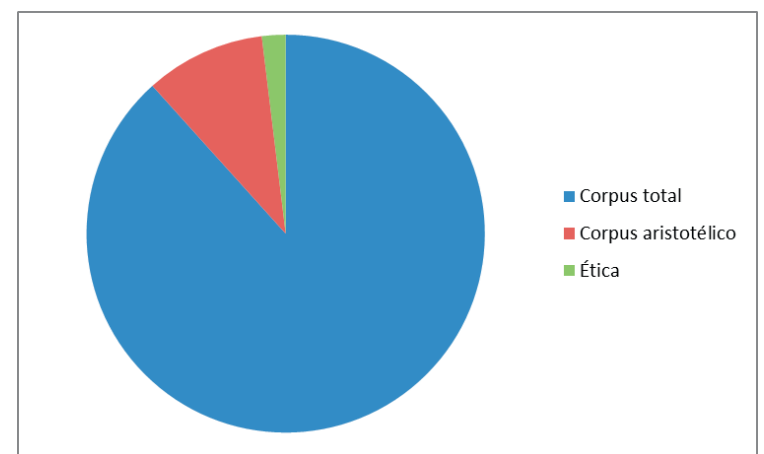

FIGURA 14. CONTABILIZACIÓN GLOBAL DEL CORPUS MANUSCRITO ARISTOTÉLICO Y LA REPRESENTACIÓN EN ÉL DE LA ÉTICA EN EL ÁMBITO UNIVERSITARIO SALMANTINO. (Elaboración propia).

De entre éstos, el género que queda más representado, como no es de extrañar en el ámbito académico en el que nos encontramos, es el del comentario. 


\subsubsection{Incunables en la biblioteca universitaria de Salamanca}

Entre las 459 entradas de incunables e impresos recientes (ca. I500-I505) que recoge el catálogo de Riesco Bravo, 57 se corresponden con materia aristotélica. Predomina la Lógica, la Filosofía natural y la Metafísica. Son dos los ejemplares que recogen comentarios a la Moral aristotélica: Quaestiones super libros Ethicorum Aristotelis, cum textu de Juan Versor (Salamanca, BUS, BG/I I39) y los Comentarios de Pedro de Osma corregidos por su discípulo Fernando de Roa (Salamanca, BUS, BG/I 309 y 310). La materia de Moral aristotélica transmitida de forma indirecta queda representada por los ejemplares del De regimine principum de Gil de Roma en su versión latina (Salamanca, BUS, BG/I II2 (I)) y los dos ejemplares de la traducción y glosa por Juan García de Castrojeriz (Salamanca, BUS, BG/I I3I y I36). Se incluyen también dos obras de santo Tomás de Aquino, titulada la primera Commentaria in libros politicorum Aristotelis, absoluta a Petro Alverniense et enmendata a Johanne Ferrario (Salamanca, BUS, BG/I I59(2)) y la segunda, Commentaria in libros politicorum Aristotelis cum textu, interprete Leonardo Aretino (Salamanca, BUS, BG/I I6(2)). Casi todas estas ediciones salieron de prensas venecianas, excepto dos: los Commentarii in libros Ethicorum Aristotelis, correcti per Magistrum de Roa de Pedro de Osma (1496), impreso en Salamanca, y el De regimine principum traducido, impreso en Sevilla en I494.

De todos los ejemplares aristotélicos, de nuevo se observa la abundancia de comentarios (I3), expositiones (I6) y quaestiones (20). Cómputo que corrobora el tipo de metodología y finalidad universitaria del acercamiento al texto. Es también numerosa la nómina de autores de corte escolástico: san Alberto Magno, santo Tomás de Aquino, Gil de Roma, Juan Versor o Duns Escoto. ${ }^{66}$ Pero no llame a engaño el marbete de 'escolásticos' pues en el siglo XVI, sobre todo el Aquinate y también el voluntarista Escoto tendrán un importante papel en la evolución de la intelectualidad en Europa.

\section{CONCLUSIONES}

Mientras en el siglo XII se conocía al Filósofo por su obra dedicada a la Lógica, durante el siglo XIII, período en el que son reseñables los ataques a la obra aristotélica, se añade a este panorama la imagen de un Aristóteles físico, metafísico y, sobre todo más adelante, también moral. Esa situación explica la mayor presencia del corpus aristotélico en materia de Filosofía natural, Lógica y que la Filosofía moral aristotélica y, más en concreto la Ética, estuviera mínimamente

66. Riesco Bravo, Fulgencio: Incunables de la Biblioteca Universitaria de Salamanca. Madrid, Cuerpo Facultativo de Archiveros, Bibliotecarios y Arqueólogos, 1949. 
representada. Aun así, conviene advertir que en todas las bibliotecas, exceptuando Burgos y Burgo de Osma, encontramos varios ejemplares de la misma. Abundan los comentarios, aunque las traducciones también queden representadas, lo que se explica en la medida en que servían de base para la lectio y quaestio. Si hiciéramos un análisis global de la representación cuantitativa de traducciones y comentarios de todo el corpus aquí tratado, el resultado quedaría así:

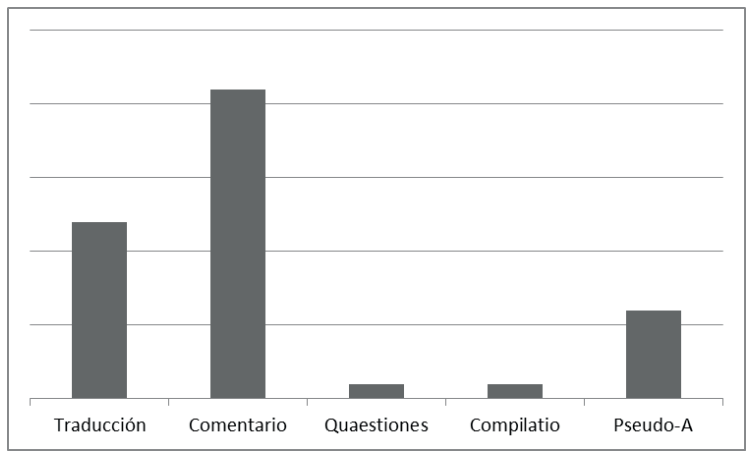

FIGURA 15. REPRESENTACIÓN DE TRADUCCIONES Y COMENTARIOS EN EL CORPUS DE BIBLIOTECAS CATEDRALICIAS Y UNIVERSITARIAS EN CASTILLA. (Elaboración propia).

Todos los testimonios son traducciones al latín (exceptuando la noticia que recoge el inventario del obispo don Gonzalo de Vivero sobre una versión en romance intermedia entre los comentarios de Averroes y la traducción de Hermann el Alemán). Entre estas, la versión de Bruni, aunque en menor proporción que la de Roberto Grosseteste, queda representada por cinco ejemplares, a los que se podrían añadir el comentario de Pedro de Osma (tres ejemplares), que se basan en la traducción del florentino. De la antigua versión de Grosseteste se localizan cuatro ejemplares, y a su difusión habría que añadir el resto de comentarios a la Ética que se basan en esta versión. De entre estos, la mayor representación (aunque, repito, nunca en términos de grandes cantidades) es la de santo Tomás de Aquino. ${ }^{67}$

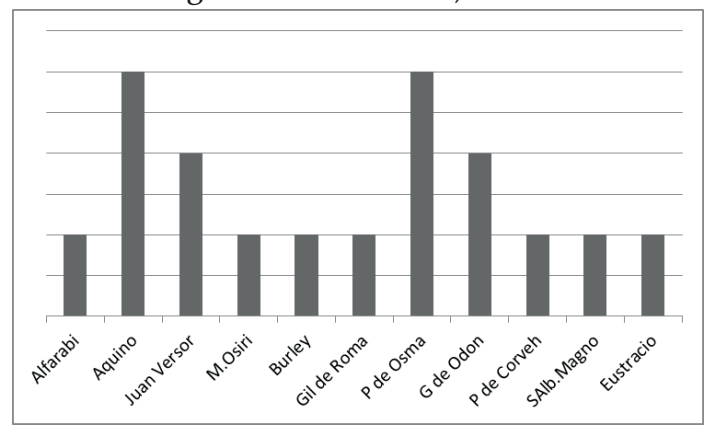

FIGURA 16. COMENTARIOS A LA ÉTICA. (Elaboración propia).

67. Tomo la tabla de un trabajo mío (todavía en prensa) que lleva el título de Aristóteles, Aristotelismo medieval y la península ibérica. Aquí modifico ligeramente el orden de aparición de los comentaristas. 
En último lugar, no extraña corroborar la influencia que supuso en este panorama la labor intelectual y cultural concentrada en la universidad salmantina. Los datos cuantitativos hablan por sí solos:

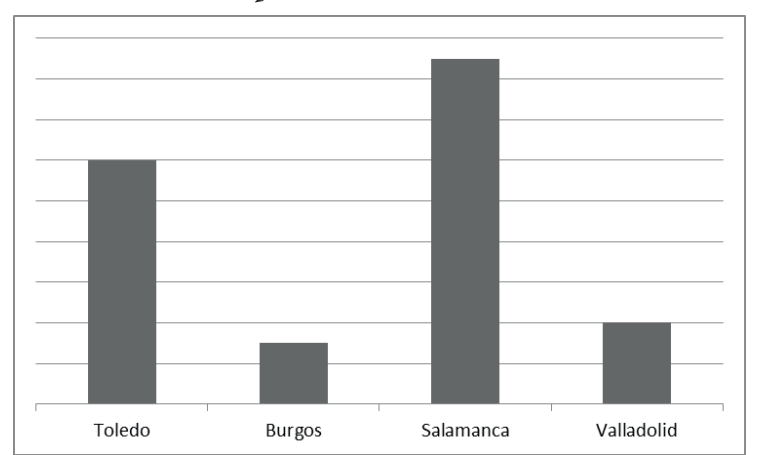

FIG. 17. CORPUS ARISTOTÉLICO EN ÁMBITOS GEOGRÁFICOS DE CASTILLA. (Elaboración propia).

Los centros de estudio de orden clerical tenían como primer objetivo la formación religiosa y litúrgica del clero. Para algunos de los estudiantes estos años de formación servirían de antesala a los estudios en Teología. No extraña, por lo tanto, la abundancia en materia de exégesis y liturgia entre los ejemplares de las bibliotecas.

También a través de la universidad medieval fue recuperado Aristóteles, y a partir de allí se configuraría su figura como maestro de Lógica. Conforme avanza el tiempo, Europa, y también Castilla, vivió una reestructuración cultural y social que influyó en y fue retroalimentada por el ámbito intelectual. Había nuevas necesidades que exigían soluciones y se planteaban nuevos dilemas doctrinales, sociales y políticos que también eran objeto de reflexión y debate en las aulas.

El siglo XIII es un momento esencial en la historia de la monarquía castellana y será también entonces cuando se observa una considerable presencia de la Ética aristotélica en las bibliotecas. El silencio del siglo XIV puede estar justificado por la amenaza del averroísmo y la acusada preocupación eclesiástica ante la teoría de la doble verdad que podría filtrarse a través de los comentarios y traducciones de la obra del Filósofo pagano. Será el siglo XV testigo de otro resurgimiento del aristotelismo y, con él, de un renacimiento de la auctoritas moral del Estagirita. La progresiva configuración de un nuevo estado político y social exigía echar mano de fuentes clásicas y racionales. El número de testimonios aumenta en los catálogos y también se amplía el tipo de lecturas con las que se accede a los textos. Es necesaria una adecuada perspectiva para percibir y, sobre todo, comprender tales variaciones. Y es que la capacidad de adaptación a diversos contextos, intereses y lectores confirma a Aristóteles como uno de los referentes más moldeables, moldeados y autorizados en el contexto intelectual europeo. 


\section{BIBLIOGRAFÍA}

AgUAdÉ Nieto, Santiago: «Las universidades y la formación intelectual del clero castellano en la Edad Media», en AguAdÉ Nieto, Santiago (coord.): Universidad, cultura y sociedad en la Edad Media. Alcalá, Universidad, 1994, pp. 159-206.

ANTElo IgLESIAS, Antonio: «Las bibliotecas del otoño medieval. Con especial referencia a las de Castilla en el siglo XV», Espacio, Tiempo y Forma, Serie 3, Historia Medieval, 4 (I99I), pp. 285-350.

Alcocer Martínez, Mariano: Historia de la Universidad de Valladolid. T.3, Expedientes de provisiones de cátedras. Valladolid, Imprenta Castellana, I92I.

Benito Ruano, Eloy: «Ámbito y ambiente de la «Escuela de Traductores de Toledo». Espacio, Tiempo y Forma, Serie 3. Historia Medieval, I3 (2000), pp. I3-28, disponible en [acceso I7 noviembre 20I7].

Beltrán de Heredia, Vicente: Cartulario de la Universidad de Salamanca (I2I8-I60o). Salamanca, Universidad, I970.

Bolton Holloway, Julia: «Diplomacy and Literature: Alfonso el Sabio's Influence on Brunetto Latino, Maestro di Dante Alighieri», en La città e il libro. Il manoscritto, la miniatura. Firenze e la Spagna. Florencia, Accademia delle Arti del Disegno, 2002, disponible en [acceso 20 noviembre 20I7].

Cacho Blecua, Juan Manuel y Lacarra, María Jesús: Historia de la literatura española. Volumen I. Entre la oralidad y la escritura: la Edad Media, dir. José Carlos-Mainer y coord. Gonzalo Pontón, Barcelona, Crítica, 2012.

CaÑas Gálvez, Francisco de Paula: Burocracia y cancillería en la corte de Juan II de Castilla (I406-I454). Estudio institucional y prosopográfico. Salamanca, Ediciones Universidad de Salamanca, 2009.

Cuenca i Almenar, Salvador: Compendio de la Ética Nicomaquea (siglo XV). Edición crítica y estudio. Zaragoza, Prensas Universitarias de Zaragoza, 2016.

Cuenca i Almenar, Salvador: «El compendio de la Ética Nicomaquea (siglo XV): relaciones entre los manuscritos castellano-aragoneses y el testimonio catalán», Romance Philology, 70 (2016), pp. 283-294.

CUenca i Almenar, Salvador: «L'Ėtica nicomaquea d'Aristòtil en un compendi català del segle XV», Anuari de la Societat Catalana de Filosofia, XXIII, (20I2), pp. 7-II9.

Cuenca i Almenar, Salvador: «Un exemple d'amplificació en els comentaris de L'Ètica nicomaquea (II37a-b): el setge de València de I364, els estrangers castellans i la virtut de l'equitat», en Casaban Moya. Enric (ed.): XIX Congrés Valencià de Filosofia. Valencia, Universidat de Valencia/Universitat Jaume I, 2012, pp. 75-82.

Del Val Valdivieso, María Isabel: «Universidad y oligarquía urbana en la Castilla Bajomedieval», en Aguadé Nieto, Santiago (coord.): Universidad, cultura y sociedad en la Edad Media. Alcalá, Universidad, I994, pp. I33-I46.

Escobar Chico, Ángel: «Aristoteles pictus: vicisitudes de la iconografía aristotélica en la España medieval y renacentista», Atalaya, I5 (2015), pp. I-2I, [fecha de consulta: 6 de noviembre 20I7] URL:

Escobar Chico, Ángel: «Hacia una caracterización de la transmisión aristotélica en la Cataluña medieval», Anuario de Estudios Medievales, 45: I (2015), pp. 299-330.

Escobar Chico, Ángel: «Presencia de Aristóteles en el Fondo Antiguo de las bibliotecas aragonesas. Apuntes para un repertorio sistémático», Alazet, I4 (2002), pp. I23-I37- 
Escobar CHico, Ángel: «Aristoteles Hispanus: Transmisión textual y pervivencia literaria de Aristóteles en España (hasta I60o)», en: Prato, G (ed.): I manoscritti greci tra riflessione e dibattito. Atti [...]. Florencia, Gonnelli, 2000, pp. 715-7I8.

ESPERABÉ de Arteaga, Enrique: Historia pragmática e interna de la Universidad de Salamanca. Salamanca, Universidad de Salamanca, I9I4.

Ferreiro Alemparte, Jaime: «Recepción de las Éticas y de la Política de Aristóteles en las Siete Partidas del Rey Sabio», Glossae: Revista de Historia del Derecho Europeo, I (I988), pp. 97-33, disponible en [acceso 20 noviembre 2017].

Fuente PÉrez, María Jesús: El estudio general de Palencia. La primera universidad hispana. Palencia, Ediciones Cálamo, 2012.

Fuente Pérez, María Jesús: «El nacimiento de la universidad de Palencia en el contexto de las universidades europeas», en FuEnte PéREz, María Jesús (coord.): El estudio general de Palencia. Historia de los ocho siglos de la Universidad española. Valladolid, Universidad de Valladolid, 20I2, pp. 69-89.

GALENDE DíAz, Juan Carlos: «La biblioteca del Colegio Mayor salmantino de san Bartolomé en el siglo XVIII», Revista General de Información y Documentación, Vol. Io: 2 (2000), pp. 33-69, disponible en [acceso I5 noviembre 20I7].

García, Máximo y Sobaler, Ma Ángeles: Estudios en homenaje al profesor Teófanes Egido. Valladolid, 2004.

García y García, Antonio et alii: Catálogo de los manuscritos e incunables de la catedral de Córdoba. Salamanca, Universidad Pontificia, Monte de Piedad y Caja de Ahorros de Córdoba, 1976.

GonzÁlvez Ruiz, Ramón: Hombres y libros de Toledo. Madrid, Fundación Ramón Areces, 1997 .

Guijarro, Susana: «Las escuelas y la formación del clero de las catedrales en las diócesis castellano-leonesas (siglos XI al XV)», en de la IgLEsia DuARTE, José Ignacio (coord.), X Semana de Estudios Medievales: La enseñanza en la Edad Media. Logroño, Instituto de Estudios Riojanos, 2000, pp. 6I-96.

GullléN TORRALBA, Juan: «La biblioteca de la Catedral. La Colombina», en La Biblioteca Colombina y Capitular. Sevilla, Consejería de Cultura y Medio Ambiente. Junta de Andalucía. Asesoría Quinto Centenario, I990.

GutiÉRrez del CAÑo, Marcelino: Códices y Manuscritos que se conservan en la Biblioteca de la Universidad de Valladolid. Valladolid, Universidad de Valladolid, I988.

Hernández, Francisco J. y Linehan, P.: The Mozarabic Cardinal. The Life and Times of Gonzalo Pérez Gudiel. Florencia, Sismel-Edizioni del Galluzzo, 2004.

Hernández Montes, Benigno: Biblioteca de Juan de Segovia: Edición y comentario de escritura de donación (coll. «Bibliotheca theologica hispana», ser. $2^{\text {a }}$, t. 3. Madrid, CSIC, I984.

Heusch Carlos: «Entre didacticismo y heterodoxia. Vicisitudes de la Ética aristotélica en la España escolástica (siglos XIII-XIV)», La Corónica: A Journal of Medieval Hispanic Languages, Literatures, and Cultures, I9: 2 (I990-I99I), pp. 89-99.

Lilao Franca, Oscar y Castrillo González, Carmen (eds.): Catálogo de Manuscritos de la Biblioteca Universitaria de Salamanca. Salamanca, Universidad de Salamanca, I997.

Lines, David A.: Aristotle's Ethics in the Italian Renaissance (ca. I300-I650). Leiden; Boston, E.J. Brill, 2002.

LoHr, Charles : Commentateurs d'Aristote au moyen-âge latin. Bibliographie de la littérature secondaire récente. Friburg, Éditions universitaires, 1967.

López MarTínez, Nicolás: «La biblioteca de don Luis de Acuña en I496», Hispania: Revista española de historia, 78 (I960), pp. 8I-IIO. 
Marcos Rodríguez, Florencio: «La antigua biblioteca de la catedral de Salamanca», Hispania Sacra, I4 (I96I), pp. 28I-3I9.

Martínez Díez, Gonzalo: «Palencia, la primera universidad de España», en Torremocha Hernández, Margarita (coord.): El Estudio General de Palencia. Historia de los ocho siglos de la universidad española. Valladolid, Universidad de Valladolid, 20I2, pp. 47-68.

MenÉndez PidAl, Ramón: España, eslabón entre la Cristiandad y el Islam. Madrid, Espasa Calpe, 1956.

Portilla GonZÁlez, Aída: «El saber medieval en Castilla (ss. XIII-XIV): la biblioteca de la catedral de Sigüenza», Medievalismo, 24 (20I4), pp. 32I-35I, disponible en [acceso I5 noviembre 20I7].

Ramos Merino, Juan Luis: «La librería de la Catedral de Burgos en el siglo XV: una aproximación», Boletín de la Institución Fernán González, I: 266 (2003), pp. I8I-I92.

Rashdall, Hastings: The Universities of Europe in the Middle Ages. Oxford, Clarendon Press, 1936.

Reyes Asenjo, Laura: Catálogo de los libros manuscritos de la biblioteca capitular de Palencia. Palencia, Institución Tello Téllez de Meneses, 2006.

Riesco Bravo, Fulgencio: Incunables de la Biblioteca Universitaria de Salamanca. Madrid, Cuerpo Facultativo de Archiveros, Bibliotecarios y Arqueólogos, I949.

Rodríguez, Ferdinando: Catálogo degli Incunaboli della Biblioteca del Colegio di Spagna a Bologna. Bolonia, Real Colegio de España en Bolonia, I972, vol. 2, pp. 699-7I2.

Rojo Orcajo, Timoteo: Catálogo descriptivo de los códices que se conservan en la santa Iglesia Catedral de Burgo de Osma. Madrid, Tipografía de Archivos, I929.

SÁNCHEZ SÁNCHEZ, Daniel: «Catedral y Universidad, una relación secular», en Historia de la Universidad de Salamanca I. Trayectoria y vinculaciones. Salamanca, Ediciones Universidad de Salamanca, 2002, 405-434.

VAlero Moreno, José Miguel: «Formas del aristotelismo ético-político en la Castilla del siglo XV», en ed. Lines, David A. y Refini, Eugenio (eds.): Aristotele fatto volgare: tradizione aristotelica e cultura volgare nel Rinascimento. Pisa, ETS, 20I4, pp. 253-310. 
Calidad de Revistas

científicas Españolas

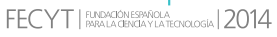

SERIE III HISTORIA MEDIEVAL

REVISTA DE LA FACULTAD DE GEOGRAFÍA E HISTORIA
AÑO 2018

ISSN: 0214-9745

E-ISSN 2340-1362

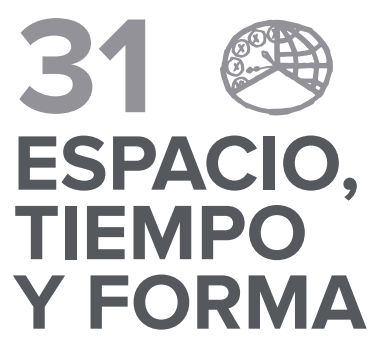

GREGoRIO DEL SER QUIJANO

Carmelo Luis López, In Memoriam

\section{Artículos · Articles}

29 SOHA ABBOUd Haggar

Un resumen del tratado jurídico de Al-Tafrí: el Manuscrito Árabe 1233 del Monasterio de El Escorial y su supuesta relación con Leyes de Moros

EDUARDo Aznar VALLejo

Norma y conflicto en la navegación castellana bajomedieval

69 Carlos Barquero Goñ

Transferencias de recursos de la Orden de San Juan desde España hasta el Mediterráneo Oriental durante la Edad Media

\section{Margarita Cabrera Sánchez}

La muerte del príncipe Don Juan. Exequias y duelo en Córdoba y Sevilla durante el otoño de 1497

\section{Francisco de Paula Cañas Gálvez}

Primogenitura, continuidad dinástica y legitimitad instituciona en Castilla a principios del siglo XV: Catalina de Trastámara, Princesa de Asturias (1422-†1424)

\section{Paloma Cuenca Muñoz}

El códice visigótico de los Moralia in lob, ms. lat. 83 de la John Rylands Library de Manchester

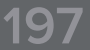

\section{JOSÉ MARÍA DIAGO JIMÉNEZ}

Las instituciones educativas de carácter religioso en el reino hispanovisigodo de los siglos VI y VII a través de los cánones conciliares y las reglas monásticas

MARÍA Díez Yáñez

La Ética aristotélica en Castilla: las bibliotecas universitarias medievales y prerrenacentistas

\section{Estefanía Ferrer del Río}

Rodrigo de Mendoza, I Marqués del Cenete y I Conde del Cid: paralelismos entre su biografía y su pretendida genealogía

\section{ALEJANDRo García Morilla \\ Escritura publicitaria de transición: entre la visigótica y la carolina.} El paradigma burgalés

María Dolores García Oliva

Señores contra campesinos: un conflicto por la tierra en Mirabel a finales de la Edad Media y principios de los Tiempos Modernos (1488-c. 1520)
34.3 jaime García Carpintero lópez de Mota

La hospitalidad santiaguista a finales de la Edad Media: el proyecto de reconstrucción del hospital de Alarcón

377 LAURA DA GRACIA

La posesión agraria individual en los registros notariales de Fuente el Sol (1481-1482

4.03 Mauricio Herrero Jiménez

El valor de los documentos reales en los procesos de la Real Chancillería de Valladolid

431 Miguel José López-Guadalupe Pallarés

Procesos de señorialización en los concejos de la Extremadura castellano-leonesa. Un estado de la cuestión

455 Ángel Martínez Catalán

Las rentas decimales del cabildo catedralicio de Cuenca a inicios del siglo XV (1400-1432)

4.83 Gonzalo Oliva Manso

Cien años de moneda en Castilla (1172-1268). El siglo del maravedí de oro

521 jesús Olivet García-Dorado

El cabildo de curas y beneficiados de Toledo en la segunda mitad del siglo XV. Composición y aspectos institucionales (1455-1488)

547 Mariel PÉrez

Clérigos rurales, comunidades y formación de las estructuras parroquiales en la diócesis de León (siglos XI-XIII)

575 Milagros Plaza Pedroche

La Orden de Calatrava en la Baja Edad Media (1350-1500): repaso historiográfico

597 Pedro Andrés Porras Arboledas

La pervivencia del Fuero de Cuenca en los inicios de la Modernidad: el testimonio de los fueros de Consuegra y Requena

619 Juan Pablo Rubio Sadia

Los mozárabes frente al rito romano: balance historiográfico de una relación polémica

SANDRA SUÁREZ GARCíA

Los habices de la Vega de Granada como forma de conocimiento del reino nazarí y su transformación tras la conquista: la alquería de La Zubia 


\section{1}

\section{ESPACIO,}

\section{TIEMPO}

\section{Y FORMA}

SERIE III HISTORIA MEDIEVAL

REVISTA DE LA FACULTAD DE GEOGRAFÍA E HISTORIA

\section{De medievalistas ilustres · On Renowned Medievalists}

671 Francisco Abad Nebot

Entradas para un Diccionario

\section{Libros $\cdot$ Books}

679 Almagro Vidal, Clara, Paisajes medievales en el Campo de Calatrava (CARLos BARQUero GoÑI)

681 Carvajal Castro, Álvaro, Bajo la máscara del Regnum. La monarquía asturleonesa en León (854-1037) (JOSÉ MANUEL RODRÍGUEZ GARCíA)

683 Fuente Pérez, María Jesús, Violante de Aragón, reina de Castilla (ANA ECHEVARRía ARsuaga)

687 Martín Prieto, Pablo, Historia del pensamiento medieval: filosofia y teología (FRANCISCO LEÓN FLORIDO)

689 Pardo de Guevara y Valdés, Eduardo (ed.), Mujeres con poder en la Galiciamedieval (siglos XIII-XV). Estudios, biografías y documentos (ENRIQUe CANTERA MONTENEGRO)

693 Ríos Saloma, Martín (ed.), El mundo de los conquistadores (Jessica Ramírez MéndeZ)

690 Solórzano Telechea, Jesús, Arízaga Bolumburu, Beatriz y BOCHACA, Michel (eds.), Las sociedades portuarias de la Europa atlántica en la Edad Media (ANTONIO ORTEGA VILLOSLADA)

703 VAL VALDIVIEso, María Isabel del (coord.), El agua en el
imaginario medieval. Los reinos ibéricos en la Baja Edad Media (MARÍA Jesús Fuente)

707 Villar García, Luis Miguel, Archivo Municipal de Segovia. Documentación medieval, 1166-1474 (ENRIQUE CANTERA MONTENEGRO) 